\title{
The Gametic Non-Lethal Gene Gal on Chromosome 5 Is Indispensable for the Transmission of the Co-Induced Semidwarfing Gene $d 60$ in Rice
}

\author{
Motonori Tomita ${ }^{1, *(D)}$ and Takatoshi Tanisaka ${ }^{2}$ \\ 1 Laboratory of Genetics and Genome Engineering, Research Institute of Green Science and Technology, \\ Shizuoka University, Shizuoka 422-8529, Japan \\ 2 Laboratory of Breeding, Faculty of Agriculture, Kyoto University, Kyoto 606, Japan; t_tanisa@kiui.ac.jp \\ * Correspondence: tomita.motonori@shizuoka.ac.jp; Tel.: +81-54-238-4929
}

Received: 2 September 2019; Accepted: 11 October 2019; Published: 17 December 2019

\begin{abstract}
The gametic lethal gene gal in combination with the semidwarfing gene $d 60$ causes complementary lethality in rice. Here, we attempted to ascertain the existence of gal and clarify male gamete abortion caused by $d 60$ and gal. Through the $F_{2}$ to $F_{4}$ generations derived from the cross between $\mathrm{D} 60 \mathrm{gal}$-homozygous and $d 60 \mathrm{Gal}$-homozygous, progenies of the partial sterile plants (D60d60 Galgal) were segregated in a ratio of 1 semidwarf $(1 \mathrm{~d} 60 \mathrm{~d} 60 \mathrm{Gal} \mathrm{Gal}): 2$ tall and quarter sterile (2 D60d60Galgal):6 tall (2 D60d60GalGal:1 D60D60GalGal:2 D60D60Galgal:1 D60D60galgal), which is skewed from the Mendelian ratio of 1 semidwarf:3 tall. However, the $F_{4}$ generation was derived from fertile and tall heterozygous $\mathrm{F}_{2}$ plants (D60d60GalGal), which were segregated in the Mendelian ratio of 1[semidwarf (d60d60GalGal)]:2[1 semidwarf:3 tall (D60d60GalGal)]:1[tall (D60D60GalGal)]. The backcrossing of $D 60 \mathrm{Gal}$-homozygous tall $\mathrm{F}_{4}$ plants with Hokuriku 100 resulted in fertile $\mathrm{BCF}_{1}$ and $\mathrm{BCF}_{2}$ segregated in a ratio of 1 semidwarf:3 tall, proving that $d 60$ is inherited as a single recessive gene in the D60d60 GalGal genetic background (i.e., in the absence of gal). Further, gal was localized on chromosome 5, which is evident from the deviated segregation of $d 1$ as 1:8 and linkage with simple sequence repeat (SSR) markers. Next-generation sequencing identified the candidate SNP responsible for Gal. In $\mathrm{F}_{1}$ and sterile $\mathrm{F}_{2}$, at the binucleate stage, partial pollen discontinued development. Degraded pollen lost vegetative nuclei, but second pollen mitosis raising two generative nuclei was observed. Thus, our study describes a novel genetic model for a reproductive barrier. This is the first report on such a complementary lethal gene, whose mutation allows the transmission of a co-induced valuable semidwarfing gene $d 60$.
\end{abstract}

Keywords: rice; complementary gamete lethal; non-Mendelian ratio; mapping; NGS; pollen development; pollen second mitosis

\section{Introduction}

The "Green Revolution" of the 1960s, in which the production of grain was dramatically increased through the breeding and development of semidwarf varieties of rice and wheat, is probably the greatest agricultural contribution in the history of mankind. Semidwarfness prevents plants from lodging at their full-ripe stage, making them lodging-resistant to wind and rain, enhances their adaptability for heavy manuring, and markedly improved the global productivity of rice and wheat between 1960-1990 (up to double yields of rice and quadruple yields of wheat) [1]. The semidwarf "miracle rice" variety IR8 released by the International Rice Research Institute (IRRI) responds particularly well to fertilizer inputs and produces increased yields without culm elongation [2]. The widespread adoption of IR8 brought about a "green revolution" in the monsoonal regions of Asia, where typhoons frequently 
occur during the yielding season. In addition, semidwarfness brings benefits such as erect leaf angles, reduced photoinhibition, and the possibility of planting at higher densities. For this reason, semidwarf varieties were also introduced into California and also in Latin America [3].

Several dwarf genes have been isolated, but many of these dwarf phenotypes are the result of deficiencies in the gibberellin (GA) biosynthesis pathway, which controls the levels of GA1, a final product of active GA, in the stem and leaf. The $s d 1$ alleles, on the long arm of chromosome 1 [4-6], encode a defective C20-oxidase in the gibberellin (GA) biosynthesis pathway (GA 20-oxidase, OsGA20ox2) [7-10] and mutations in the GA20-oxidase gene lead to disruptions at a late stage of the GA pathway [7]. The $s d 1$ gene confers the semidwarf phenotype with no detrimental effects on grain yield [11-13]. Although semidwarf varieties of rice have contributed to the dramatic improvement and stabilization of yields worldwide, the semidwarf stature of varieties derived from native or mutant maternal lines happen to be controlled by a single gene, $s d 1[7,9,14-16]$, as it is an oligopoly condition of $s d 1$. Both the Tanginbouzu $d 35$ and Kotake-tamanishiki $d 18-k$ genes are kaurenoic acid oxidase-defective or 3-beta hydroxylase-defective in the same GA biosynthesis pathway [17]. Other dwarf genes such as $d 11$ [18] and $s d 37$ [19], whose function is not related to the GA biosynthesis pathway, were certainly identified. However, their practical use in breeding has not yet proceeded. A little genetic source of current semidwarf rice cultivars has a risk for environmental change. Thus, it is necessary to acquire a wider range of semidwarfng genes to cope with future environmental changes.

In order to identify a novel alternative semidwarf gene to $s d 1$, we conducted gene analyses focusing on Hokuriku 100, a mutant breeding rice strain with a $20 \%$ shorter culm than the Koshihikari variety. Hokuriku 100 was developed through a large-scale mutation breeding operation using ${ }^{60} \mathrm{Co}$ irradiation to overcome the lodging weakness of Koshihikari [20]. The first author analyzed a mutation of Hokuriku $100[21,22]$ and observed abnormal segregation in the ratio of 40 semidwarf:294 tall between Koshihikari and Hokuriku 100, which is skewed from the expected 1:3 ratio of the $F_{2}$ population. The first author suspected that this might be attributed to the partial seed sterility of $25 \%$ in the $\mathrm{F}_{1}$ and some of the $\mathrm{F}_{2}$ tall plants. An $\mathrm{F}_{3}$ progeny test was conducted in which both semidwarfness and seed sterility were observed, and the following hypotheses were proposed: 1) Koshihikari carries a gametic lethal gene, gal;2) Hokuriku 100 carries a gametic non-lethal gene, Gal, mutated from gal, as well as its activator, $d 60 ; 3)$ male and female gametes carrying both gal and $d 60$ are lethal. To date, there is no evidence that the supposed semidwarf gene $d 60$ is inherited as a single recessive gene according to the ratio of 1D60D60:2D60d60:1d60d60. However, double dwarfness due to a combination of $d 60$ and $s d 1$ was obtained via skewed segregation, and therefore $d 60$ is regarded as an independent allele of $s d 1$ [23].

The objectives of this study were: (1) to prove the existence of the supposed gametic lethal gene gal by genetic analysis of the skewed segregation of semidwarfness accompanied by seed sterility from $\mathrm{F}_{1}$ to $\mathrm{F}_{4}$ generations; (2) to confirm the Mendelian ratio of the $d 60$ allele in the genetic background of the gametic non-lethal allele $\mathrm{Gal}$ homozygous in $\mathrm{F}_{4}$ and $\mathrm{BCF}_{1}$; (3) to identify the chromosomal localization of $g a l$ by the deviated segregation of linked morphological markers, linkage analysis with DNA markers, and whole genome sequencing with next-generation sequencing (NGS); and (4) to clarify the male-gamete abortion caused by $d 60$ and gal through cytological observation.

\section{Materials and Methods}

\subsection{Genetic Analysis of $d 60$ and Gal}

$F_{1}$ to $F_{3}$ of Koshihikari $\times$ Hokuriku 100 were retested in this study. Then, a progeny test was carried out on $100 \mathrm{~F}_{3}$ lines ( 30 plants per line) raised from randomly selected $\mathrm{F}_{2}$ plants. The $\mathrm{F}_{3}$ lines were grouped into four classes as shown in Figure 1, where the author identified two types of segregation lines: segregation type I and segregation type II. Segregation type I was composed of $22 \mathrm{~F}_{3}$ lines, derived from partially sterile long-culm $\mathrm{F}_{2}$ plants, and was observed to segregate both for culm length and seed fertility, as for $\mathrm{F}_{2}$ segregation. Four $\mathrm{F}_{3}$ lines ( 25 plants/line) were selected from these 22 segregation type $I$ lines, and the seed set percentage of each $\mathrm{F}_{3}$ plant was counted. Then, $100 \mathrm{~F}_{4}$ lines 
(30 plants/line) were raised from each of the $\mathrm{F}_{3}$ plants. Segregation type II lines were composed of 22 $\mathrm{F}_{3}$ lines, derived from fertile long-culm $\mathrm{F}_{2}$ plants, and were observed to segregate for culm length, but not seed fertility. $100 \mathrm{~F}_{4}$ lines ( 30 plants/line) were raised from each plant of $4 \mathrm{~F}_{3}$ lines ( 25 plants/line) selected from 23 segregation type II lines. The $\mathrm{F}_{4}$ plants were investigated for culm length, seed fertility, and days to heading.

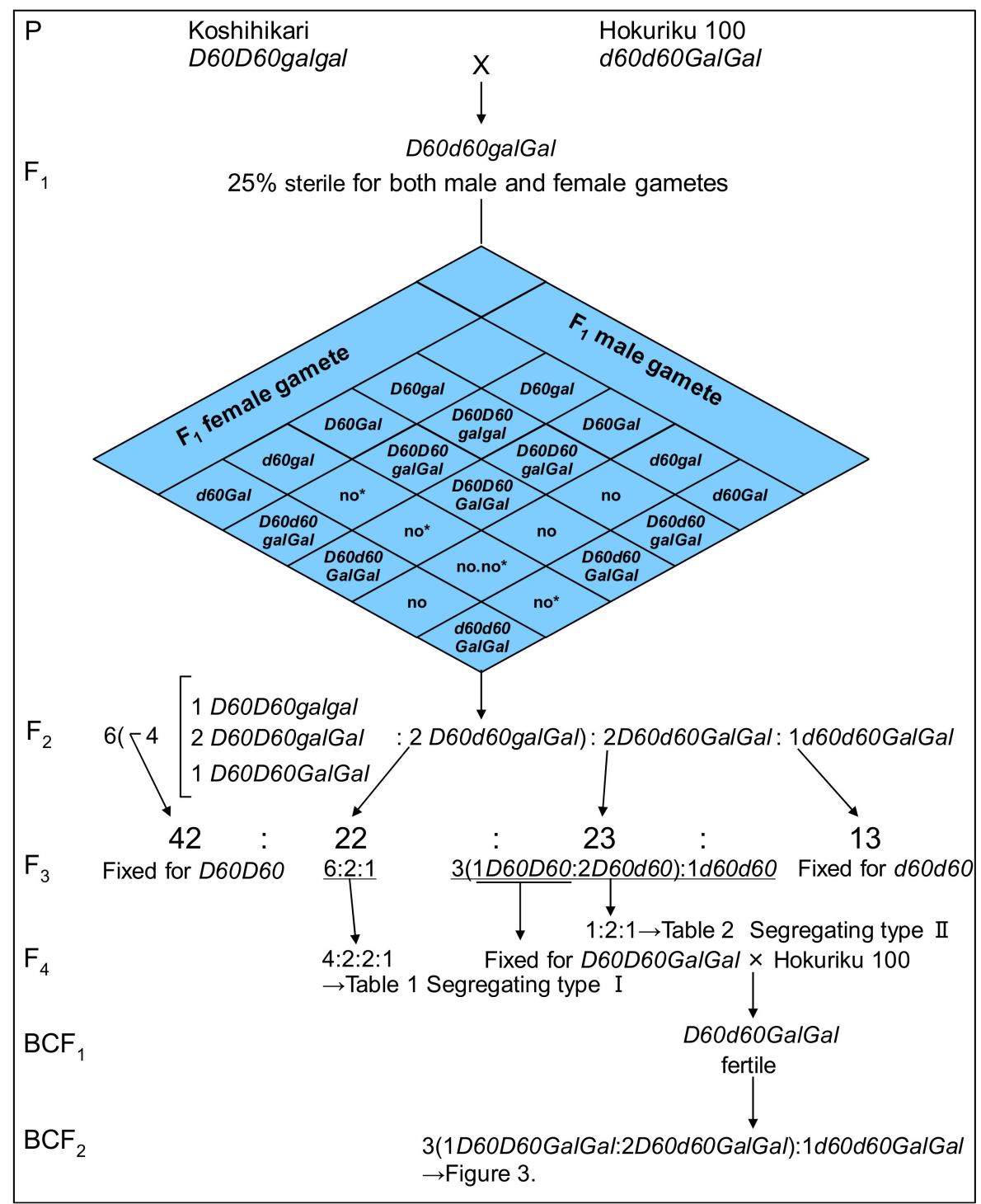

Figure 1. Complementary gamete lethal genetically confirmed through the generation from $F_{1}$ to $F_{4}$ and backcross with D60Gal homozygous line. The semidwarfing allele and tall allele were designated as $d 60$ and D60, respectively, and the gametic lethal gene gal (activated by $d 60$ ) in Koshihikari, and that the induced opposite allele Gal, a gametic non-lethal allele, in Hokuriku 100 were hypothesized. This hypothesis enables the $\mathrm{F}_{2}$ progenies of Koshihikari (D60D60galgal) $\times$ Hokuriku 100 (d60d60GalGal) to segregate into the ratio of 1 semidwarf ( $1 \mathrm{~d} 60 \mathrm{~d} 60 \mathrm{GalGal}): 2$ tall and quarter sterile (2 D60d60 Galgal): 6 tall (2 D60d60GalGal:1 D60D60GalGal:2 D60D60Galgal:1 D60D60galgal), because of the gamete lethality of both male and female gametes carrying gal and $d 60$.

Six $\mathrm{F}_{4}$ plants were randomly selected from long fixated $\mathrm{F}_{4}$ lines, genotype D60D60GalGal, in segregation type II, and were backcrossed with Hokuriku 100. Six $\mathrm{BCF}_{1}$ plants and $248 \mathrm{BCF}_{2}$ plants were investigated for culm length, seed fertility, and days to heading.

Plants used in this study were planted $10 \mathrm{~cm}$ apart with $30 \mathrm{~cm}$ between rows in the experimental field of the Faculty of Agriculture, Tottori University, Tottori, Japan. 


\subsection{Genetic Mapping}

In order to determine the chromosomal locations of the gametocidal gene gal, we conducted genetic linkage analyses of gal on the basis that the segregation ratios of the marker genes linked to gal do not fit the Mendelian ratio of 3:1. For the analyses, we developed $F_{2}$ hybrids of the Koshihikari d60Gal line (Koshihikari*7//Koshihikari/Hokuriku 100) and 23 marker gene lineages, which were selected such that they cover all rice chromosomes, taking into account the expectation that the segregation ratios for the marker genes linked to them in the $\mathrm{F}_{2}$ differ from the Mendelian ratio of 3:1; in other words, when a recessive marker gene is fully linked to gal, this ratio will be $8: 1$. The Koshihiakri d60Gal line is a isogenic Koshihiakri having $d 60$ and $G a l$, which was developed by seven times of continuous backcrossing with a recurrent parent Koshihikari and a non-recurrent parent of the $d 60$ homozygous segregant in the $\mathrm{F}_{2}$ of Koshihikari $\times$ Hokuriku100.

A chromosome segment substitution line KF2-11-75 (D60D60galgal) that carries a segment of Kasalath chromosome 5 in the Koshihikari background was crossed with the Koshihikari d60Gal line (d60d60 Gal Gal), and homozygous plants for $d 60(\mathrm{n}=202)$ were selected from the progenies grown from $\mathrm{F}_{2}$ seeds $(\mathrm{n}=1854)$. Then, the $d 60 \mathrm{Gal}$ homozygous plants were planted at the Field Science Center. DNA was extracted from the leaves of each short-culm plant, and tested for recombination ratios of Gal with simple sequence repeat (SSR) markers that were polymorphic between Kasalath and Koshihikari. Thirty-six SSR markers on chromosome 5 were used to delimit the chromosomal regions bearing Gal.

\subsection{NGS Analysis}

The semidwarfing gene $d 60$ was transferred into Koshihikari by consecutive backcrosses to prepare a semidwarf Koshihikari named Koshihikari d60Gal line. Whole-genome analysis was conducted using the Koshihikari d60Gal line and Koshihikari (D60gal). Genomic DNAs were extracted from each cultivar using the hexadecyltrimethylammonium bromide (CTAB) method. Genomic DNA was tagged and fragmented to average 500-bp long using Nextera®transposome. After purification of the transposome using DNA Clean and Concentrator ${ }^{\mathrm{TM}}-5$ (Zymo Research, Irvine, CA, USA), adaptors for fixation on the flow cell were synthesized at both ends of each fragment using polymerase chain reaction (PCR). Then, the DNA fragments were subjected to size selection using AMPure XP magnetic beads (Beckman Coulter, Brea, CA, USA). Finally, qualitative and quantitative measurements using a Fragment Analyzer ${ }^{\mathrm{TM}}$ (Advanced Analytical Technologies) and Qubit ${ }^{\circledR} 2.0$ Fluorometer (Life Technologies; Thermo Fisher Scientific, Inc., Waltham, MA, USA) were performed to prepare a DNA library for NGS. The resulting sequenced reads were mapped with BWA software using the Nipponbare genome as a reference, followed by the detection of Single Nucleotide Polymorphisms (SNPs) and Indels using SamTools software.

\subsection{Pollen Fertility}

The fertility of male gametes was examined using $10 \mathrm{~F}_{1}$ plants and $40 \mathrm{~F}_{2}$ plants (D60d60Galgal) following the cross between Koshihikari and Hokuriku 100. Both parents were also examined. Male gamete growth stages were estimated from the auricle length between the flag leaf and the next leaf. Ten panicles were sampled from each plant several times before the meiotic stage (auricle length $-10 \mathrm{~cm})$ to the trinucleate pollen stage $(+15 \mathrm{~cm})$. Sampled panicles were fixed in formalin-acetic alcohol (FAA) for $48 \mathrm{~h}$ and subsequently stored in 70\% ethanol. Microspore specimens were prepared by the acetocarmine squash method and observed under a compound microscope. The developmental processes of male gametes were examined by using $10 \mathrm{~F}_{1}$ and $40 \mathrm{~F}_{2}$ plants. The classification by Kihara and Hirayoshi [24] was adopted for the pollen development process. The diameters of 250 pollen grains per glume were measured at the trinucleate stage with an eyepiece micrometer at $1000 \times$ magnification. The percentage of spikelet fertility was calculated on the basis of the number of filled and unfilled spikelets for each harvested panicle. 


\section{Results}

\subsection{Genotyping of $d 60$ and Gal Loci through $F_{1}$ to $F_{4}$}

$\mathrm{F}_{1}$ plants of Koshihikari (tall) $\times$ Hokuriku 100 (semidwarf) showed tall phenotypes similar to Koshihikari, but averaged $27.6 \%$ unfilled spikelets. $F_{2}$ progenies showed a bi-modal curve with regard to culm length distribution, and were phenotypically classified into 32 semidwarf plants with erect leaves and 278 tall plants. However, this segregation ratio significantly deviated from the 1 semidwarf:3 tall ratio expected from a single recessive gene segregation. In addition to this skewed segregation, the tall $\mathrm{F}_{2}$ plants included 71 partially spikelet sterile plants, similar to $\mathrm{F}_{1}$. Therefore, the $\mathrm{F}_{2}$ population was comprised of three phenotypes; tall and fertile such as Koshihikari, tall and a quarter sterile such as $F_{1}$, and semidwarf and fertile such as Hokuriku 100. The first author speculated that the quarter sterility might be important in revealing the skewed segregation of Hokuriku 100 semidwarfness, so 100 randomly selected $F_{2}$ plants were also used to carry out a progeny test of $F_{3}$ ( 30 plants per line) in this study.

Four phenotypic classes were observed in the $\mathrm{F}_{3}$ population, as shown in Figure 1: $13 \mathrm{~F}_{3}$ lines derived from semidwarf $\mathrm{F}_{2}$ plants were uniform for semidwarfness and normal fertility; $22 \mathrm{~F}_{3}$ lines derived from quarter sterile $\mathrm{F}_{2}$ plants were segregated into tall plants, tall and quarter sterile plants, and semidwarf plants as for $\mathrm{F}_{2}$ (segregation type $\mathrm{I}$ ); $65 \mathrm{~F}_{3}$ lines derived from tall and fertile $\mathrm{F}_{2}$ plants were classified as either uniform for tallness and normal fertility (42 lines) or segregated into semidwarf plants and tall plants in accordance with a Mendelian 1:3 ratio (23 lines, segregation type II). These data were almost the same as previous data [21,22] and raised the hypothesis that the semidwarfness of Hokuriku 100 is controlled by a single recessive gene, and that the quarter sterility of tall parents results in the observed skewed segregation of semidwarfness to less than $25 \%$ of the next generation. Namely, the semidwarfing allele and tall allele were designated as $d 60$ and D60, respectively, and the first author hypothesized that the gametic lethal gene gal (activated by d60) must be present in Koshihikari, and that the induced opposite allele Gal, a gametic non-lethal allele, must be present in Hokuriku 100. As Figure 1 indicates, this hypothesis enables the $F_{2}$ progenies of Koshihikari $($ D60D60galgal) $\times$ Hokuriku 100 (d60d60 GalGal) to segregate into the ratio of 1 semidwarf (1 d60d60GalGal):2 tall and quarter sterile (2 D60d60Galgal):6 tall (2 D60d60GalGal:1 D60D60GalGal:2 D60D60Galgal:1 D60D60galgal), because of the gametic lethality of both male and female gametes carrying gal and $d 60$. The observed segregation ratio of 13:22:23:42 in the $\mathrm{F}_{3}$ classification represents a good fit to the theoretical ratio of 1 d60d60GalGal:2 D60d60Galgal:2 D60d60GalGal:4 (1 D60D60GalGal:2 D60D60Galgal:1 D60D60galgal) $\left(\chi^{2}=0.49,0.90<p<0.95\right)$ based on the above hypothesis.

Table 1 shows representative distributions of culm length and seed fertility in $100 \mathrm{~F}_{4}$ lines from segregation type $\mathrm{I}_{\text {. }} \mathrm{F}_{4}$ lines were classified to four classes, as for $\mathrm{F}_{3}$, on the basis of frequency distribution for culm length and seed fertility. All plants from $11 \mathrm{~F}_{4}$ lines derived from semidwarf $\mathrm{F}_{3}$ plants with an average $93.6 \%$ seed set percentage showed semidwarfness and normal seed fertility with over $90 \%$ seed set percentage. Twenty-four $\mathrm{F}_{4}$ lines from partially sterile long $\mathrm{F}_{3}$ plants with an average seed set percentage of $70.9 \%$ were segregated into semidwarf plants $(n=61)$, partially sterile long plants $(n=114)$, and fertile long plants (406). Plants pooled from these $24 \mathrm{~F}_{4}$ lines showed a good fit to the 1:2:6 ratio expected from the existence of $g a l\left(\chi^{2}=2.86,0.20<p<0.30\right)$ (Figure 2A). On the other hand, $65 \mathrm{~F}_{4}$ lines from fertile long $\mathrm{F}_{3}$ plants with an average seed set percentage of $94.7 \%$ showed normal seed fertility with over $90 \%$ seed set percentage. As in Figure 2B, 19 of these 65 lines were segregated into semidwarf plants (122) and long plants (356), showing a good fit to single recessive gene segregation ratio 1:3 $\left(\chi^{2}=0.07,0.90<p<0.95\right)$. The other $46 \mathrm{~F}_{4}$ lines were fixed as long plants. This $\mathrm{F}_{4}$ classification showed a good fit to the theoretical ratio 1 d60d60GalGal:2 D60d60Galgal:2 D60d60GalGal:4 D60D60 homozygous [1GalGal:2Galgal:1galgal], as expected from existence of the $\mathrm{gal} / \mathrm{Gal}$ locus $\left(\chi^{2}=0.67,0.80<p<0.90\right)$. 
Table 1. Classification of $\mathrm{F}_{4}$ lines of Segregating type I based on segregation of culm length and seed fertility.

\begin{tabular}{|c|c|c|c|c|c|c|c|c|c|c|c|c|c|c|c|c|c|c|c|c|c|}
\hline \multirow{3}{*}{\multicolumn{2}{|c|}{ Phenotype and Genotype of $F_{3}$}} & \multicolumn{17}{|c|}{ Frequency Distribution $^{1)}$ of Culm Length and Seed Fertility in Representative $F_{4}$ Lines } & \multirow{3}{*}{$\begin{array}{c}\mathrm{F}_{4} \text { Lines } \\
\text { Observed } \\
\text { No. }\end{array}$} & \multirow{2}{*}{\multicolumn{2}{|c|}{ Expected }} \\
\hline & & \multicolumn{17}{|c|}{ Culm Length (cm) } & & & \\
\hline & & 50 & & & & & 60 & & & & & 70 & & & & & 80 & & & No. & Ratio \\
\hline \multirow{5}{*}{$\begin{array}{l}\text { Hokuriku } 100 \text { type } \\
\text { (semidwarf) }\end{array}$} & \multirow{5}{*}{ d60d60GalGal } & & & & 5 & 9 & 5 & 5 & 1 & & & & & & & & & & \multirow{5}{*}{11} & \multirow{5}{*}{11.1} & \multirow{5}{*}{1} \\
\hline & & 1 & 1 & 2 & 7 & 9 & 2 & & 2 & 1 & & & & & & & & & & & \\
\hline & & & & 4 & 5 & 6 & 5 & 3 & 2 & & & & & & & & & & & & \\
\hline & & 1 & 4 & 6 & 7 & 5 & 1 & 1 & & & & & & & & & & & & & \\
\hline & & & 1 & 2 & 8 & 8 & 1 & 2 & & & & & & & & & & & & & \\
\hline \multirow{5}{*}{$\begin{array}{c}\text { Koshihikari type } \\
\text { (tall and approx. } \\
30 \% \text { sterile) }\end{array}$} & \multirow{5}{*}{ D60d60Galgal } & & & & & 1 & & & & & & $\begin{array}{c}1 \\
(1)\end{array}$ & 6 & $\begin{array}{c}5 \\
(1)\end{array}$ & $\begin{array}{c}7 \\
(1)\end{array}$ & $\begin{array}{l}2 \\
1\end{array}$ & 2 & & \multirow{5}{*}{24} & \multirow{5}{*}{22.2} & \multirow{5}{*}{2} \\
\hline & & & 2 & & & 3 & 1 & & & 1 & & $\begin{array}{c}3 \\
(1)\end{array}$ & 5 & $\begin{array}{c}6 \\
(2)\end{array}$ & 4 & 1 & & & & & \\
\hline & & & & & & & & 1 & & 1 & & 1 & 1 & $\begin{array}{c}3 \\
(2) \\
\end{array}$ & $\begin{array}{c}7 \\
(3) \\
\end{array}$ & $\begin{array}{c}5 \\
(1) \\
\end{array}$ & $\begin{array}{c}2 \\
(1) \\
\end{array}$ & 2 & & & \\
\hline & & & & 1 & 1 & & & 2 & 1 & 3 & $\begin{array}{c}2 \\
(1)\end{array}$ & 1 & $\begin{array}{l}3 \\
(3)\end{array}$ & 3 & 7 & 1 & 1 & & & & \\
\hline & & 1 & & 1 & & & & & 1 & 3 & 1 & & $\begin{array}{c}3 \\
(1)\end{array}$ & 2 & $\begin{array}{c}6 \\
(2)\end{array}$ & $\begin{array}{c}5 \\
(3)\end{array}$ & 3 & & & & \\
\hline \multirow{10}{*}{ Koshihikari type (tall) } & \multirow{5}{*}{ D60d60GalGal } & & & 5 & & & 1 & 1 & & & & 1 & 2 & 5 & 6 & 3 & 1 & & \multirow{5}{*}{19} & \multirow{5}{*}{22.2} & \multirow{5}{*}{2} \\
\hline & & & & 1 & 2 & & 2 & 1 & 2 & 1 & & 3 & 2 & 6 & 4 & 2 & & & & & \\
\hline & & & & & 1 & & 3 & 1 & 1 & & & & 3 & 2 & 3 & 5 & 4 & 2 & & & \\
\hline & & & 1 & 1 & 1 & 1 & 1 & & & 1 & 3 & 3 & 4 & 3 & 3 & 3 & & & & & \\
\hline & & & & 1 & & 2 & & & & 2 & 1 & 5 & & 5 & 4 & 3 & 2 & & & & \\
\hline & \multirow{5}{*}{$\begin{array}{l}\text { D60D60GalGal } \\
\text { D60D60Galgal } \\
\text { D60D60galgal }\end{array}$} & & & & & & & & & & 3 & 5 & 1 & 6 & 3 & 3 & 2 & 2 & \multirow{5}{*}{46} & \multirow{5}{*}{44.4} & \multirow{5}{*}{4} \\
\hline & & & & & & & & & & & 1 & 2 & 9 & 8 & 5 & & 1 & & & & \\
\hline & & & & & & & & & & & & 2 & 2 & 8 & 3 & 5 & 2 & & & & \\
\hline & & & & & & & & & & 1 & 3 & 3 & 4 & 8 & 5 & 1 & & 1 & & & \\
\hline & & & & & & & & & & & & 1 & 5 & 8 & 6 & 4 & 1 & & & & \\
\hline \multirow{2}{*}{\multicolumn{2}{|c|}{ Total }} & & & & & & & & & & & & & & & & & & 100 & 100 & \\
\hline & & \multicolumn{20}{|c|}{ Test for two-gene segregation (1:2:2:4): $\mathrm{X}^{2}=0.67,0.80<p<0.90$} \\
\hline
\end{tabular}

1) Each lane shows No. of plants in a $F_{4}$ line. Figures in parenthesis shows No. of partially sterile plants. 


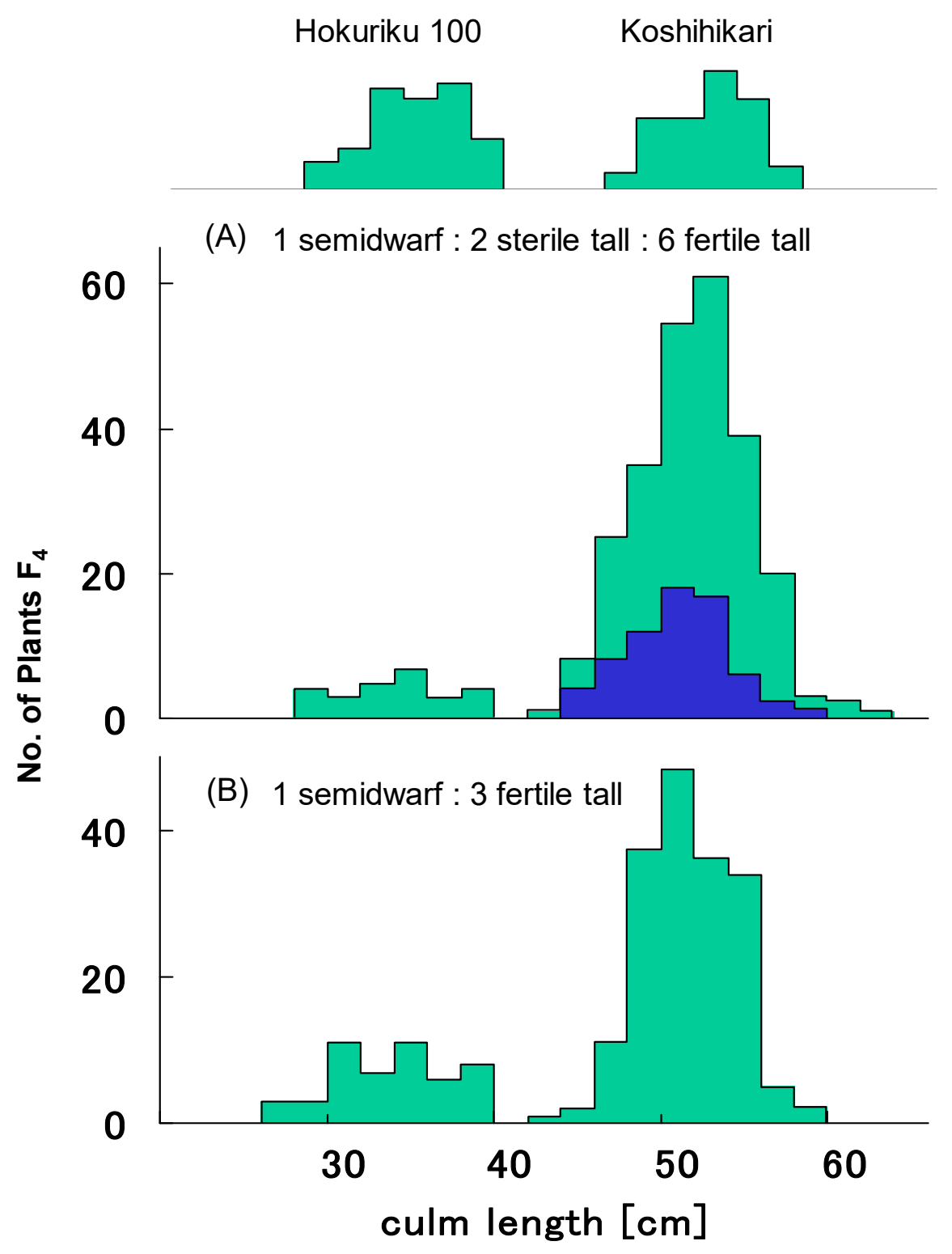

Figure 2. Frequency distribution of culm length in pooled $\mathrm{F}_{4}$ progenies derived from segregation type $I_{3}$. (A) Pooled $F_{4}$ progenies of sterile $24 F_{3}$ plants were segregated into semidwarf plants $(n=61)$, partially sterile long plants $(n=114)$, and fertile long plants $(406)$, which showed a good fit to the 1:2:6 ratio expected from the existence of $g a l\left(\chi^{2}=2.86,0.20<p<0.30\right)$. (B) Pooled $\mathrm{F}_{4}$ progenies of fertile $19 \mathrm{~F}_{3}$ plants were segregated into semidwarf plants (122) and long plants (356), showing a good fit to single recessive gene segregation ratio $1: 3\left(\chi^{2}=0.07,0.90<p<0.95\right)$.

3.2. d60 is Inherited as a Single Recessive Gene in the Non-Gamete Lethal Gal-Homozygous Background

All the $\mathrm{F}_{4}$ plants from segregation type II had normal seed fertility of over $90 \%$; so, $100 \mathrm{~F}_{4}$ lines were classified according to the frequency distribution for culm length. Table 2 shows the representative frequency distributions for the culm length in several lines of each class. All the $\mathrm{F}_{4}$ plants in 24 lines from semidwarf $\mathrm{F}_{3}$ plants showed semidwarfism. Forty-nine out of $76 \mathrm{~F}_{4}$ lines from long $\mathrm{F}_{3}$ plants segregated into a 141 semidwarf:440 long plants ratio, which is a good fit with the theoretical ratio of 1 semidwarf: 3 long expected if semidwarfism is controlled by a single recessive gene $\left(\chi^{2}=0.17,0.50<\right.$ $p<0.70$ ). The remaining $27 \mathrm{~F}_{4}$ lines were all fixed as long plants. This $\mathrm{F}_{4}$ ratio of 24:49:27 showed a good fit to the theoretical 1:2:1 ratio expected from a single recessive gene model of semidwarfness $\left(\chi^{2}=0.22,0.80<p<0.90\right)$. 
Table 2. Classification of $\mathrm{F}_{4}$ lines of segregating type II based on segregation of culm length.

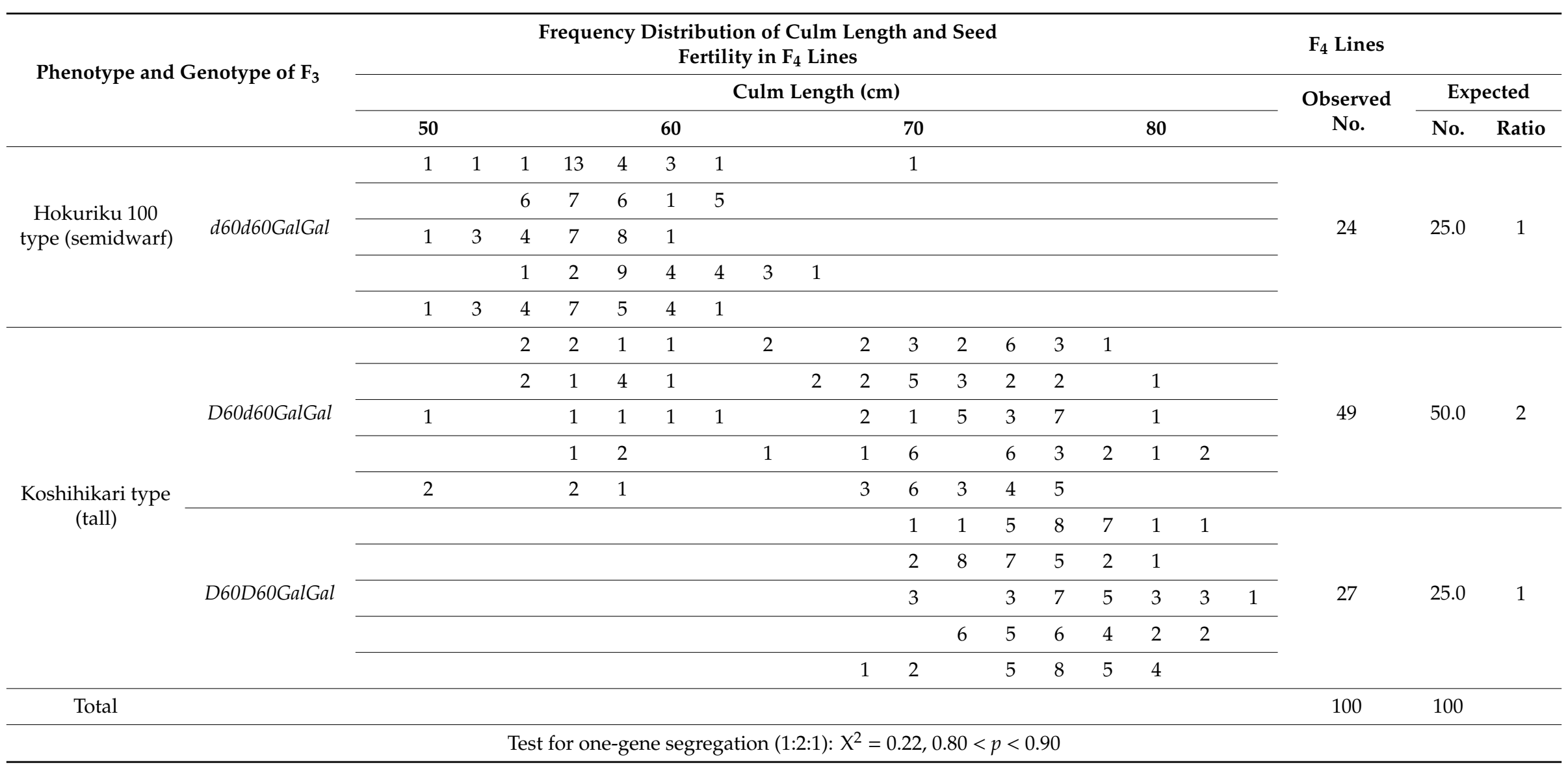


Six Koshihikari-type long $\mathrm{F}_{4}$ plants were randomly selected from 27 long $\mathrm{F}_{4}$ lines, genotype D60D60GalGal, in segregation type II and were backcrossed with Hokuriku 100. $\mathrm{BCF}_{1}$ plants showed normal fertility with a seed set of $96.0 \%$ and a pollen fertility of $97-98 \%$. Figure 3 shows the segregation of $\mathrm{BCF}_{2}$ plants as 67 semidwarf:181 long plants (Figure 4), which shows a good fit to the theoretical 1:3 ratio expected from a single recessive gene model $\left(\chi^{2}=0.54,0.30<p<0.50\right)$. Therefore, $d 60$ is inherited as a single recessive gene in the $060 \mathrm{~d} 60 \mathrm{Gal} \mathrm{Gal} \mathrm{genetic} \mathrm{background} \mathrm{(i.e.,} \mathrm{in} \mathrm{the} \mathrm{absence} \mathrm{of} g a l$ ). The plant types of segregants were clearly classified based on the phenotype, as shown in Figure 4.

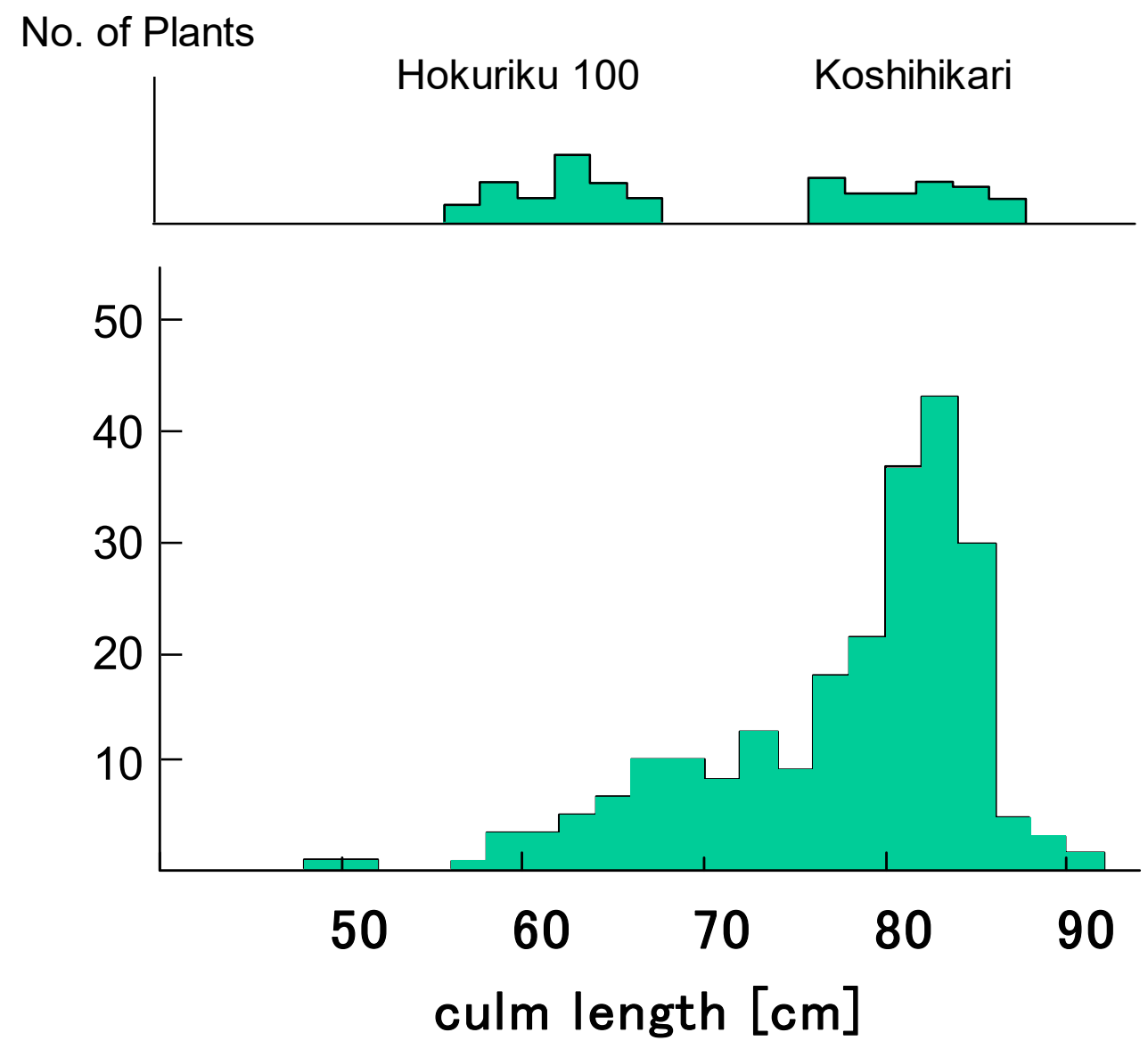

Figure 3. Frequency distribution for culm length in the $\mathrm{BCF}_{2}$ progenies of D60D60GalGal line $\times$ Hokuriku100 (d60d60GalGal). $\mathrm{BCF}_{2}$ plants segregated as 67 semidwarf:181 long plants, which shows a good fit to the theoretical 1:3 ratio expected from a single recessive gene model $\left(\chi^{2}=0.54,0.30<\right.$ $p<0.50$ ). Therefore, $d 60$ is inherited as a single recessive gene in the D60d60GalGal genetic background (i.e., in the absence of $g a l$ ).

\subsection{Genetic Mapping of Gal Loci}

Genetic linkage analysis of the $\mathrm{F}_{2}$ progenies of the cross between the Koshihikari d60Gal line (d60d60 Gal Gal) and a line carrying a gene marker $d 1$ on chromosome 5 showed that the segregation ratio of wild type to $d 1$ homozygote was 263:34 (Figure 5). This is a marked distortion from the Mendelian segregation ratio, but it is close to the theoretical segregation ratio of $8: 1$ at the $d 1$ locus $\left(\chi^{2}=0.03,0.80<p<0.90\right)$, when completely linked to the gal locus, indicating a genetic linkage between $d 1$ and gal loci on chromosome 5. Next, the Koshihikari d60Gal line was crossed with chromosome segment substitution lines that carry segments of chromosome 5 of the indica cultivar 'Kasalath' in the background of the japonica cultivar 'Koshihikari'. Short-culm homozygous (d60d60GalGal) plants in the resulting $F_{2}$ progenies (Figure 6) were examined for genetic linkage by using SSR markers located on chromosomes 5, thereby achieving fine mapping of the Gal loci. Three markers-namely, RM18102, RM18107, and RM6034-in the region 7.0 Mb away from the distal end, were liked with Gal with 
recombination values of 1.6, 1.2, and 0.7, respectively (Figure 6). These results indicate that the Gal locus is located around 7.0 Mb away from the distal end of the short arm of chromosome 5.

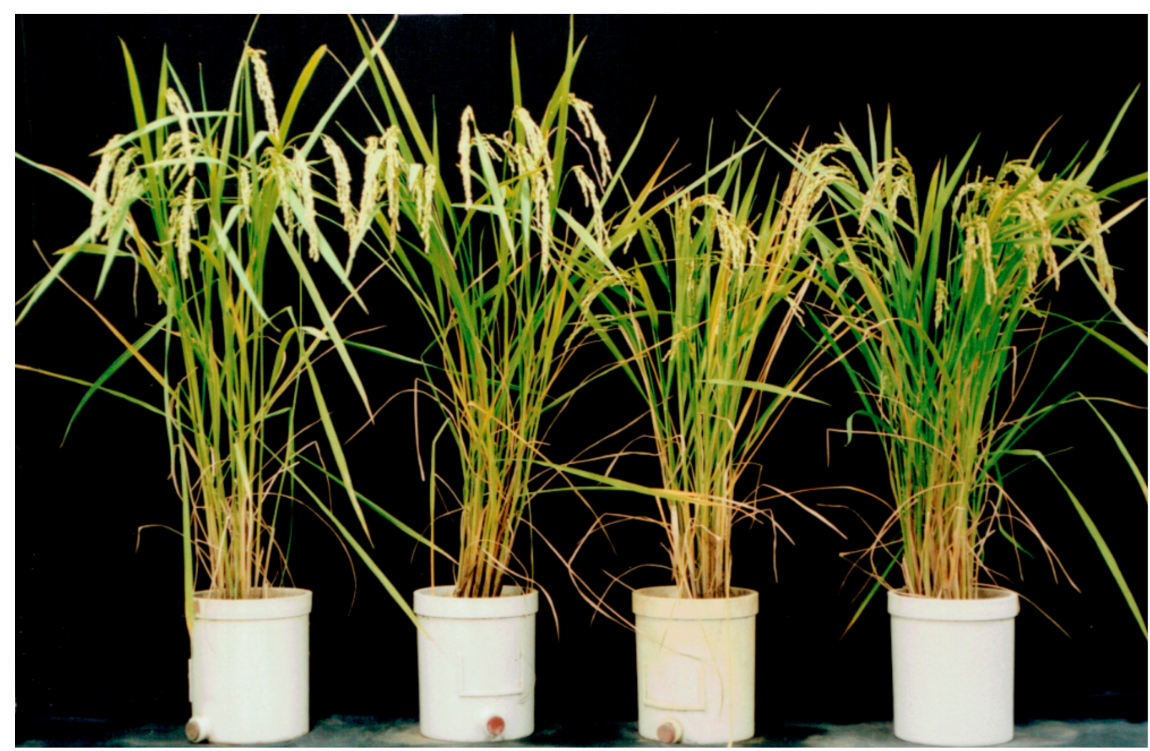

Figure 4. Segregation for plant type in the $\mathrm{BCF}_{2}$ progenies of $\mathrm{D} 60 \mathrm{D} 60 \mathrm{GalGal} \mathrm{F}_{4}$ line $\times$ Hokuriku100 (d60d60GalGal). From left to right: D60D60GalGal $\mathrm{F}_{4}$ line, Tall $\mathrm{BCF}_{2}$, Semidwarf $\mathrm{BCF}_{2}$, and Hokuriku100 (d60d60GalGal).

\subsection{Identification of Gal Responsible SNP by NGS Analysis}

Using next generation sequencer, we obtained a total read number of 66,155,260 with an average length of $124 \mathrm{bp}$ in Koshihikari and a total read number of 126,884,326 with an average length of $125 \mathrm{bp}$ in Koshihikari d60Gal. By mapping $99.91 \%$ of the reads of Koshihikari using the Nipponbare genome sequence as the reference, we attained the consensus sequence of Koshihikari with a total length of $372,912,445 \mathrm{bp}$ bearing a mean coverage of 12.79 . Then, $99.88 \%$ of reads of Koshihikari d60Gal were mapped using the consensus sequence of Koshihikari as the reference. The mean coverage was 22.42. Furthermore, we prepared vcf files of entire genomes and compared the whole-genome sequences of Koshihikari d60Gal with the virtual Koshihikari genome. As a result, we found a SNP from C to T in Koshihikari d60Gal, which was located at 7,005,876 bp from the end of the short arm of chromosome 5 in the Koshihikari genome (Figure 6). This SNP was situated almost at the center between the nearest SSR markers, RM18107 and RM6034, which were both linked with Gal. To survey DNA mutations over the 6-8 Mb region of Chromosome 5, there were no sequence alterations excerpt for this SNP, between the Koshihikari (d60gal) and Koshihikari d60Gal. We conducted a high coverage of Nextgen sequencing, so the SNP was certainly specific to the region of Koshihikari d60Gal chromosome 5. Therefore, it is highly possible that the SNP at 7,005,876 bp is responsible for the mutation of Gal. In this region, there were no annotated sequences in the rice annotation project database (https://rapdb.dna.affrc.go.jp/). However, the region surrounding the SNP showed homologies to some hypothetical proteins of humans or swallowtails. Genetically, the role of the Gal allele is to transmit $d 60$ in viable gametes, whereas that of $\mathrm{gal}$ is to reduce the transmission by complementary gamete death. Functional analysis for such unknown proteins would be a future issue to research. 
No. of individuals

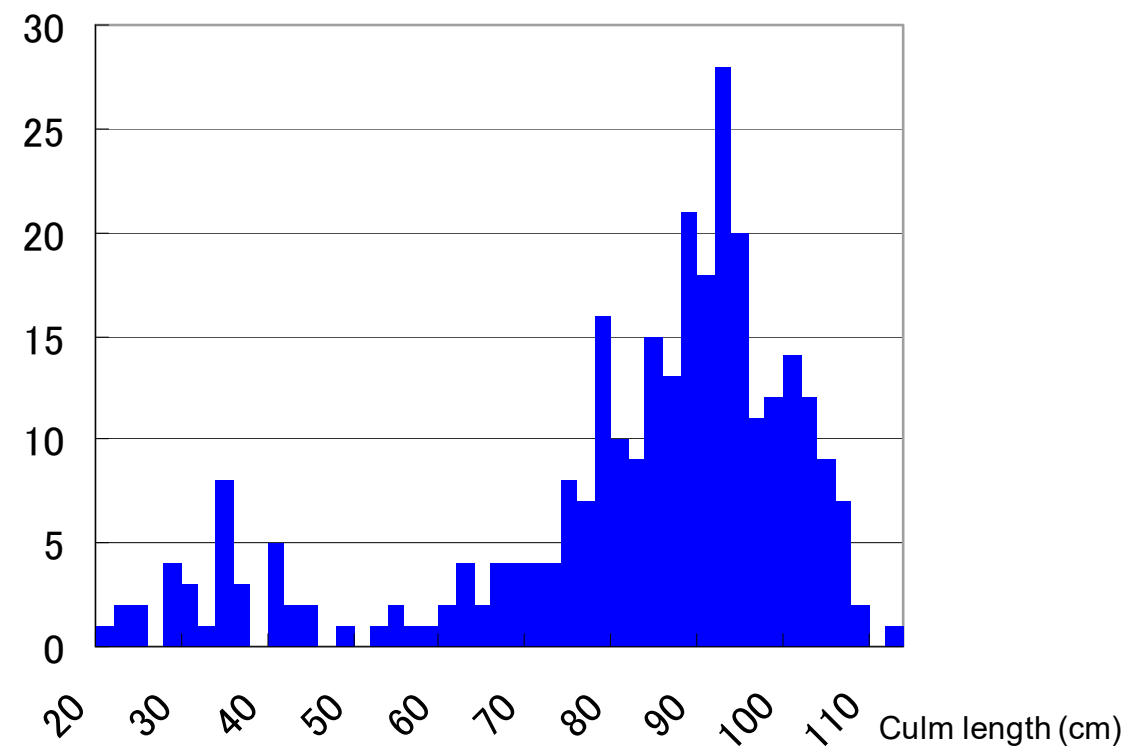

Culm length $(\mathrm{cm})$

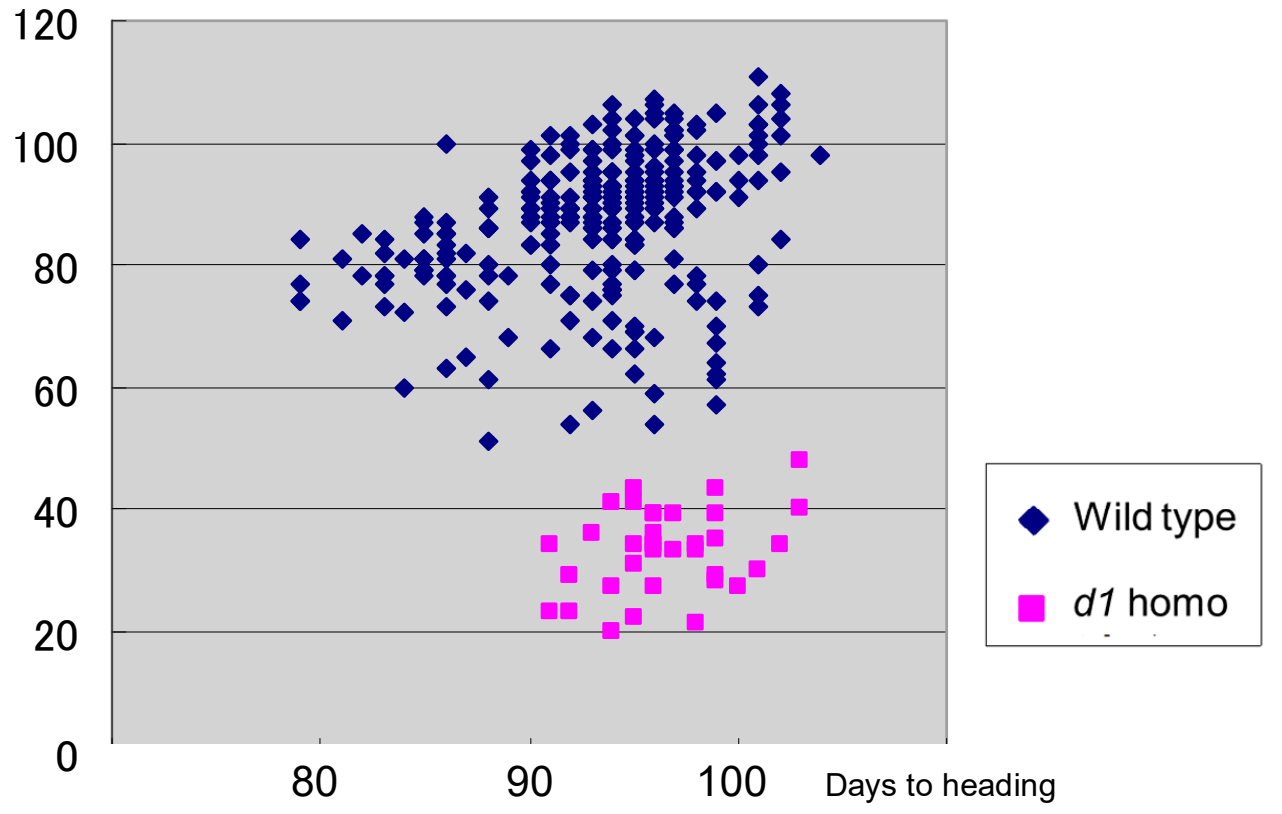

Figure 5. Little segregation of $d 1$ homozygotes in the $\mathrm{F}_{2}$ between the Koshihikari d60Gal line and $d 1$ line, showing a ratio of 263 wild type:34 $d 1$ homozygote. It is close to the theoretical segregation ratio of $8: 1$ at the $d 1$ locus $\left(x^{2}=0.03,0.80<p<0.90\right)$, when completely linked to the gal locus, indicating a genetic linkage between $d 1$ and gal loci on chromosome 5 . 


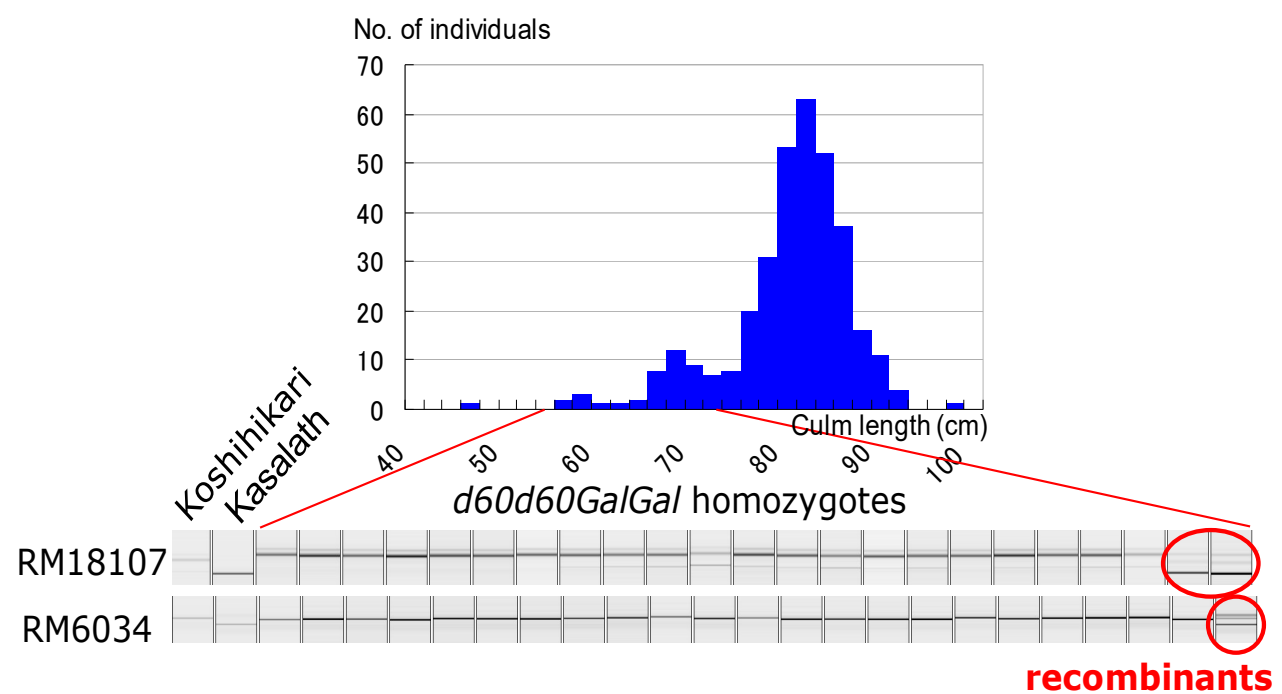

Chromosome 5

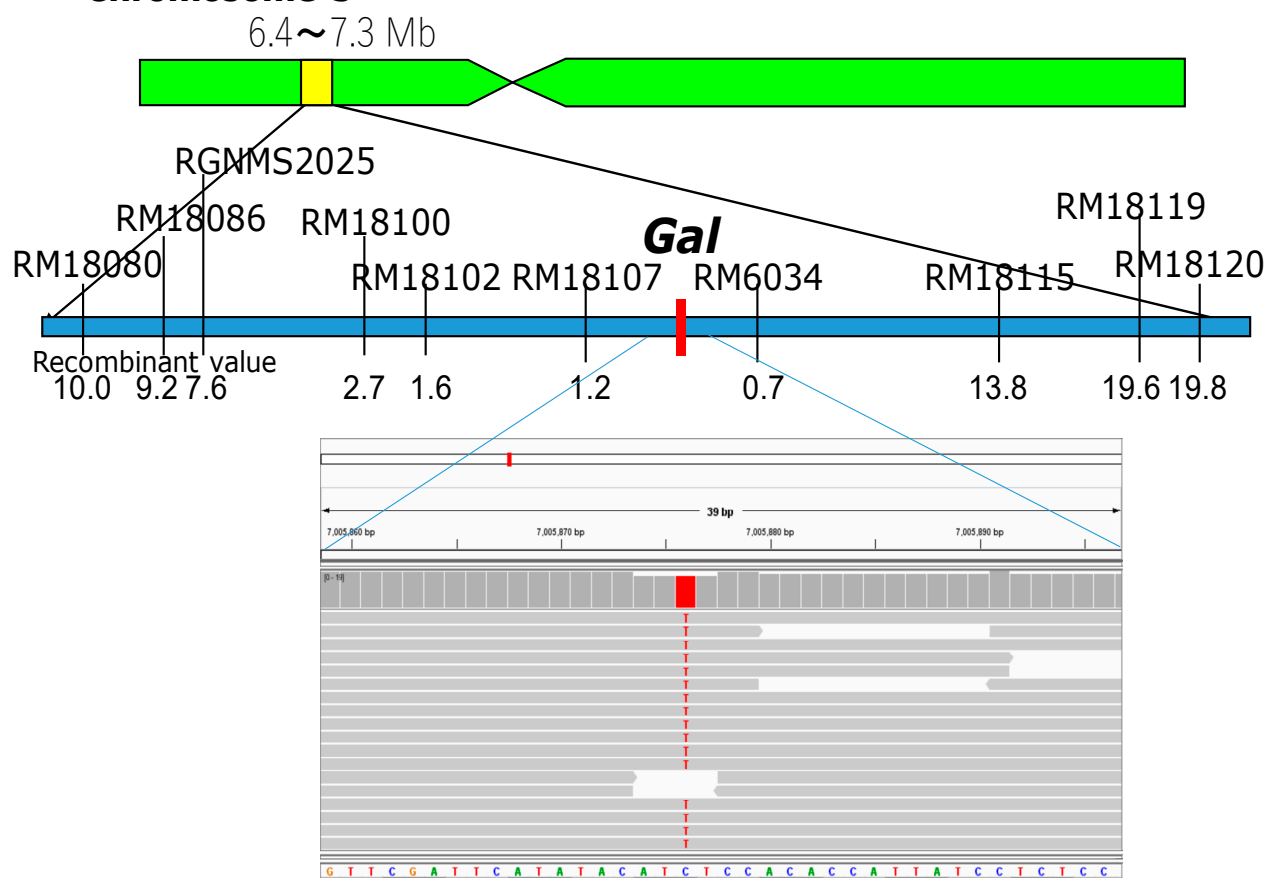

Figure 6. Molecular mapping of gamete lethal gene Gal and identification of candidate single nucleotide polymorphism (SNP) responsible for Gal by whole genome analysis using Next generation sequencer. Koshihikari d60Gal line was crossed with chromosome segment substitution line that carry segment of chromosome 5 of the indica cultivar 'Kasalath' in the background of the japonica cultivar 'Koshihikari'. Short-culm homozygous $(\mathrm{d} 60 \mathrm{~d} 60 \mathrm{GalGal})$ plants in the $\mathrm{F}_{2}$ progenies were examined for genetic linkage by using SSR markers located on chromosomes 5. Three markers-namely, RM18102, RM18107, and RM6034-in the region 7.0 Mb away from the distal end, were liked with Gal with recombination values of 1.6, 1.2, and 0.7, respectively. These results indicate that the Gal locus is located around 7.0 $\mathrm{Mb}$ away from the distal end of the short arm of chromosome 5. We found a SNP from $\mathrm{C}$ to $\mathrm{T}$ in Koshihikari d60Gal by Nextgen sequencing, which was located at 7,005,876 bp from the end of the short arm of chromosome 5 at the center between RM18107 and RM6034. It is highly possible that the $\mathrm{SNP}$ at 7,005,876 bp is responsible for the mutation of Gal.

\subsection{Coexistence of $d 60$ and Gal Lose Vegetative Nuclei but Two Generative Nuclei}

Pollen fertility was examined using panicles sampled before anthesis from both parents, $10 \mathrm{~F}_{1}$ plants (D60d60Galgal) and 40 randomly chosen $\mathrm{F}_{2}$ plants. Eight out of $40 \mathrm{~F}_{2}$ plants showed partial 
seed fertility varying from $69.2-73.8 \%$ (average, $71.9 \%$ ), and the remaining $32 \mathrm{~F}_{2}$ plants showed a normal seed set varying from $95.3-97.8 \%$ (average, $96.7 \%$ ) in maturity. Gamete development was observed. Meiosis were normally observed in all plants, which was the same as tentative data using $\mathrm{F}_{4}$ partial sterile plants [25]. After releasing from the tetrads, microspores became the first stranded stage (Figure 7A). At the single nucleate pollen stage, wall and germ pores were formed, and pollens became vacuolated (Figure 7B). During the first pollen mitosis, metaphase chromosomes were visible, and cytoplasm developed (Figure 7C). Binucleate pollens having both generative and vegetative nuclei were normally observed in all plants (Figure 7D). At the early binucleate stage, generative nuclei became enclosed in newly formed generative cells and were located opposite the pore side, apart from the vegetative nuclei (Figure 7D). However, some of the pollens discontinued development in the binucleate stage, and their vegetative nuclei became smaller in the $F_{1}$ and $25 \%$ seed-sterile $F_{2}$ plants (Figure $7 \mathrm{H}$ ). On the contrary, in the other normal pollens, generative nuclei again approached the vegetative nuclei in the late binucleate stage (Figure 7E) and were divided into two generative nuclei by the second-pollen mitosis (Figure 7F) and finally developed into normal trinucleiate pollens (Figure 7G). On the other hand, in the abortive pollens vegetative nuclei are losing, but second pollen mitosis was observed (Figure 7I), and remnant of two generative cells were observed in degraded pollens before flowering (Figure 7J).

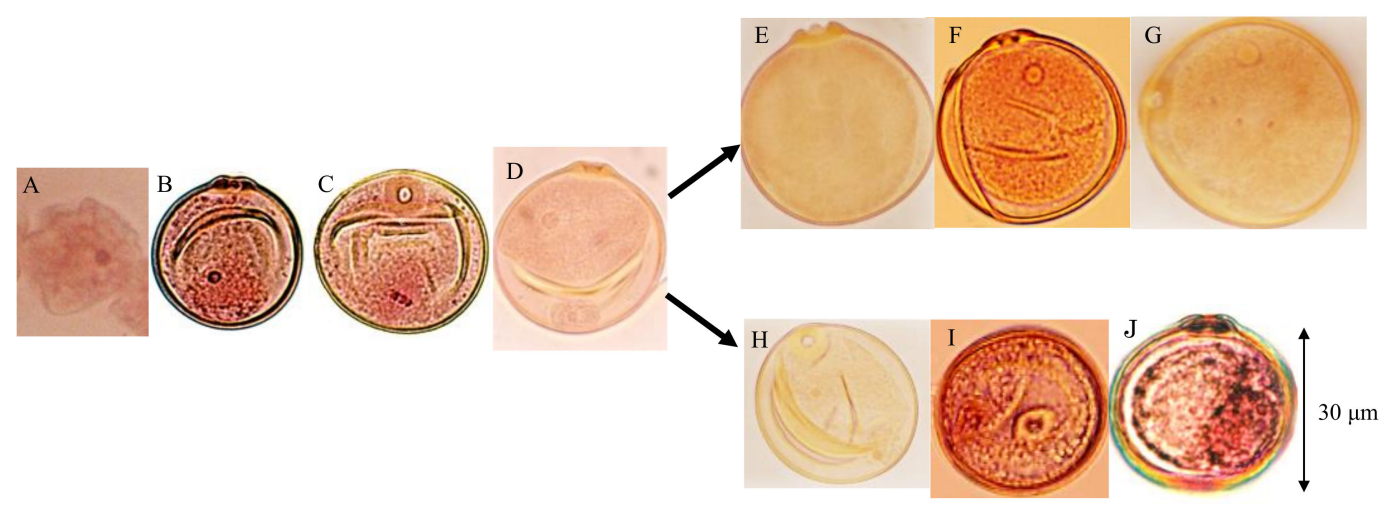

Figure 7. Developmental process of male gametes in $F_{1}$ and $25 \%$ sterile $F_{2}$ plants (genotype D60d60Galgal). (A) First shrunk pollen, (B) single-nucleate pollen, (C) metaphase of first-pollen mitosis, (D) early binucleate pollen, (E) late binucleate pollen, (F) second pollen mitosis in late binucleate pollen, (G) mature trinucleate pollen before flowering, (H) abortive binucleate pollen (genotype d60gal), (I) second pollen mitosis in abortive pollen losing vegetative nuclei $(\mathrm{d} 60 \mathrm{~g} a \mathrm{l})$, (J) remnant of two generative cells in degraded pollen before flowering (d60gal).

The degradation process of male gametes in 25\% sterile plants (genotype D60d60Galgal) are massively shown in Figure 8. The single nucleate stage is normal (Figure 8A) and enter the early binucleate stage (Figure 8B). However, the degradation of generative cell started in some binucleate pollen (Figure 8C). Degraded pollens lost vegetative nuclei and contain only a generative nuclei (Figure 8D,E) at the late binucleate stage. Second pollen mitosis is observed in normal pollens (Figure 8F) and degraded pollens, which lost vegetative nuclei (Figure 8G). Degraded pollens holding only two generative nuclei were observed among mature pollens, and finally became almost empty before flowering (Figure $8 \mathrm{H}, \mathrm{I}$ ). As a result, two distinguishable types of pollen were observed before anthesis in $F_{1}$ and $25 \%$ seed-sterile $F_{2}$ plants; degenerated vacant pollens with only a remnant of generative cell and small diameter around the median value of 36 microns (Figure 7J, Figure 8H,I), as well as normal trinucleate pollens with well-developed cytoplasm and normal diameter around the median value of 52 microns (Figure 7G, Figure 8H, I). Figure 9 shows the frequency distribution for pollen diameters in the glume of a partially seed sterile $\mathrm{F}_{2}$ plant, in which it is possible to distinguish between pollen types according to diameter. Vacant pollen diameters were distributed around a median value of $36 \mu \mathrm{m}$, while normal pollens were distributed around a median value of $52 \mu \mathrm{m}$. 


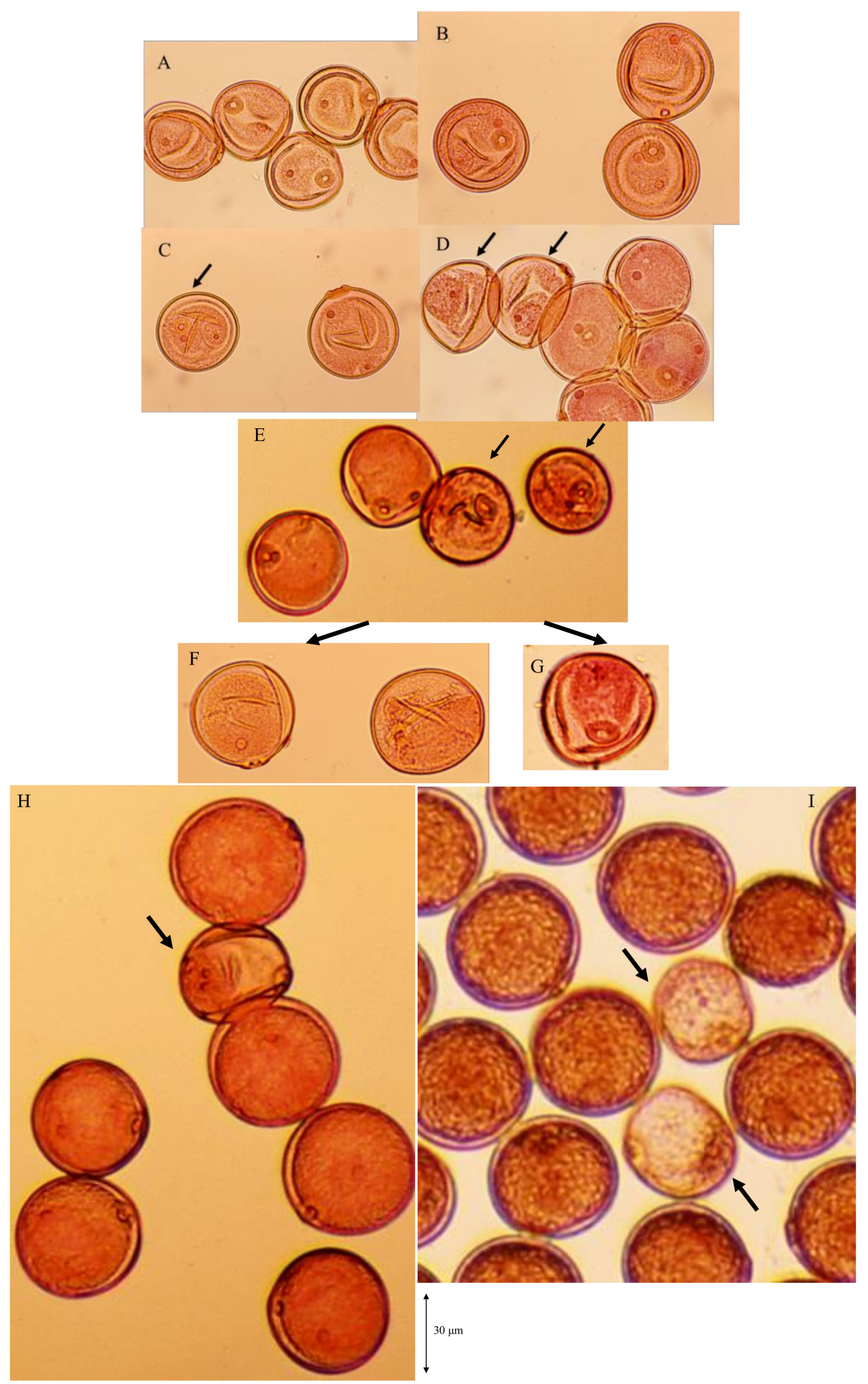

Figure 8. Massive observation of degradation process of male gametes in 25\% sterile plants (genotype D60d60Galgal). (A) single nucleate stage, (B) early binucleate pollen stage, (C) degradation of generative cell in some early binucleate pollen (arrow), (D) degraded pollen losing vegetative nuclei and holding only a generative nuclei (arrows) at the late binucleate pollen stage, (E) degraded pollen at the late binucleate pollen stage (arrows), (F) metaphase of second pollen mitosis in normal pollen, (G) metaphase of second pollen mitosis in abortive pollen, $(\mathbf{H}),(\mathbf{I})$ abortive pollen holding only two generative nuclei (arrows) among mature pollens before flowering. 


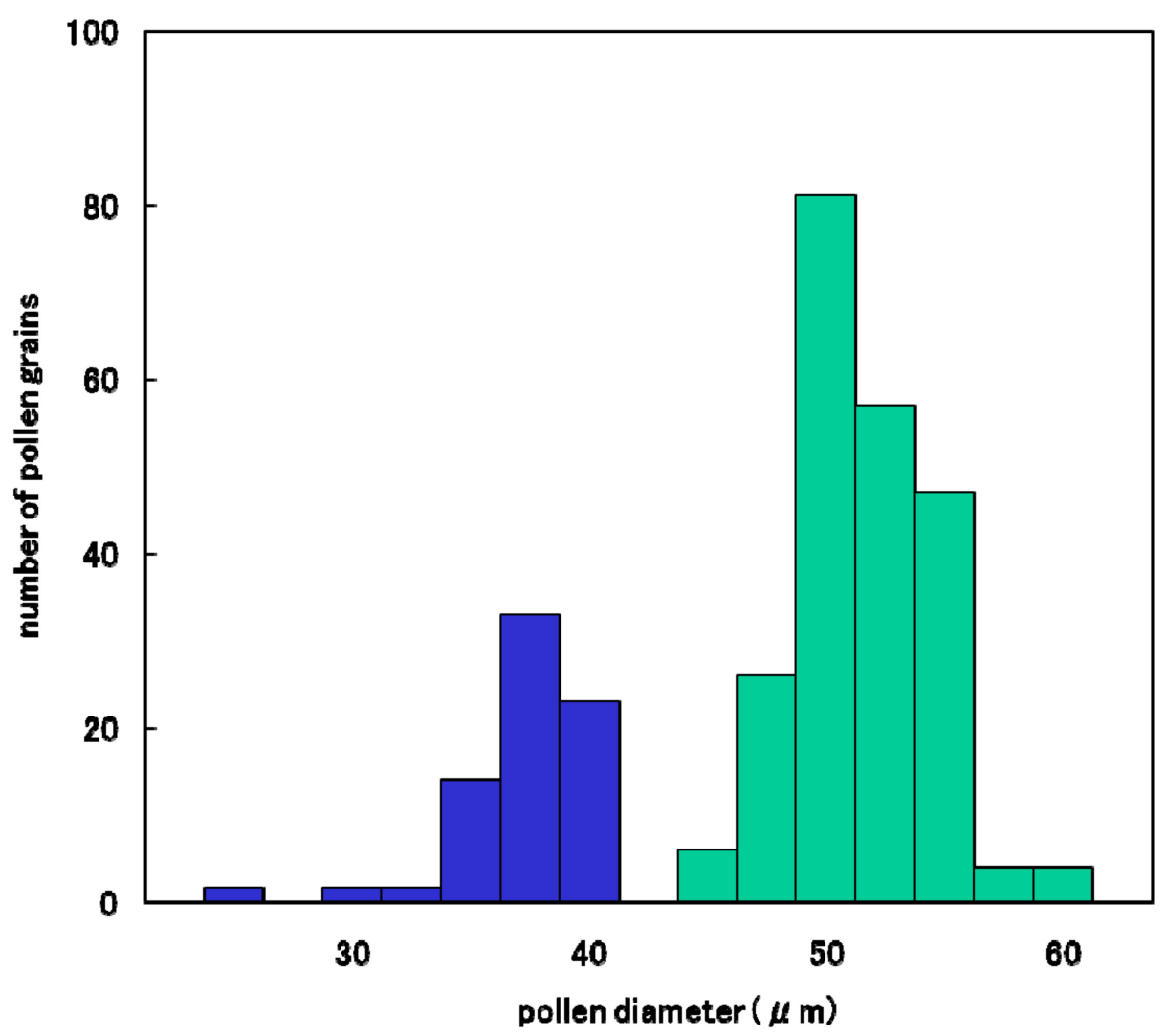

Figure 9. Frequency distribution of pollen diameter in a partially sterile $\mathrm{F}_{2}$ plant (D60d60Galgal) derived from Koshihikari $\times$ Hokuriku 100 . : Empty pollen.

The pollen fertility of each $\mathrm{F}_{2}$ plant was obtained as the rate of normal pollen with a large diameter and stainable cytoplasm. Small, empty pollen (average, 25.3\%) was observed together with stainable mature pollen in all $\mathrm{F}_{1}$ plants and eight $\mathrm{F}_{2}$ plants with partial seed setting at maturity. These partially seed sterile $\mathrm{F}_{2}$ plants had an average of $71.9 \%$ seed fertility and an average of $74.7 \%$ pollen fertility. Fewer degraded pollen grains were observed in the $32 \mathrm{~F}_{2}$ plants with nearly complete seed setting, resulting in a pollen fertility of $99.4 \%$. Figure 10 shows the relationship between pollen fertility and seed fertility in $40 \mathrm{~F}_{2}$ plants. Only partial seed sterile plants showed partial pollen sterility.

The average lethal rate of pollen in partially seed sterile $\mathrm{F}_{2}$ plants was calculated from the reduced rate of normal pollen from normal seed fertile $\mathrm{F}_{2}$ plants using the Equation (1):

$$
(99.4 \%-74.7 \% / 99.4 \%) \times 100
$$

The small, empty pollen averaged $24.8 \%$, which is in agreement with the theoretical expected frequency of the haploid genotype $d 60 \mathrm{gal}$ in eight $\mathrm{F}_{2}$ plants with a $71.9 \%$ seed set. As $75.4 \%$ of normal pollen in all $F_{1}$ plants and eight $F_{2}$ plants is fertile, the observed $27.6 \%$ unfilled spikelets must be caused by infertility of the embryo sac.

Female fertility was determined as the seed fertility. The average lethal rate of female gametes in partially seed sterile $\mathrm{F}_{2}$ plants was calculated as $25.6 \%$ from the reduced rate of normal ovules from normal seed fertile $F_{2}$ plants using the Equation (2):

$$
(96.7 \%-71.9 \% / 96.7 \%) \times 100
$$

The lethal rates of male and female gametes ( $24.8 \%$ and $25.6 \%$, respectively) coincide with the theoretical $25 \%$ lethality of male and female gametes from the coexistence of both $d 60$ and gal and 
indicates the existence of the gametic lethal gene gal. Consequently, a quarter of both sex gametes were aborted in the $\mathrm{F}_{1}$ plants and some of the tall $\mathrm{F}_{2}$ plants of Koshihikari $\times$ Hokuriku 100 (D60d60Galgal).

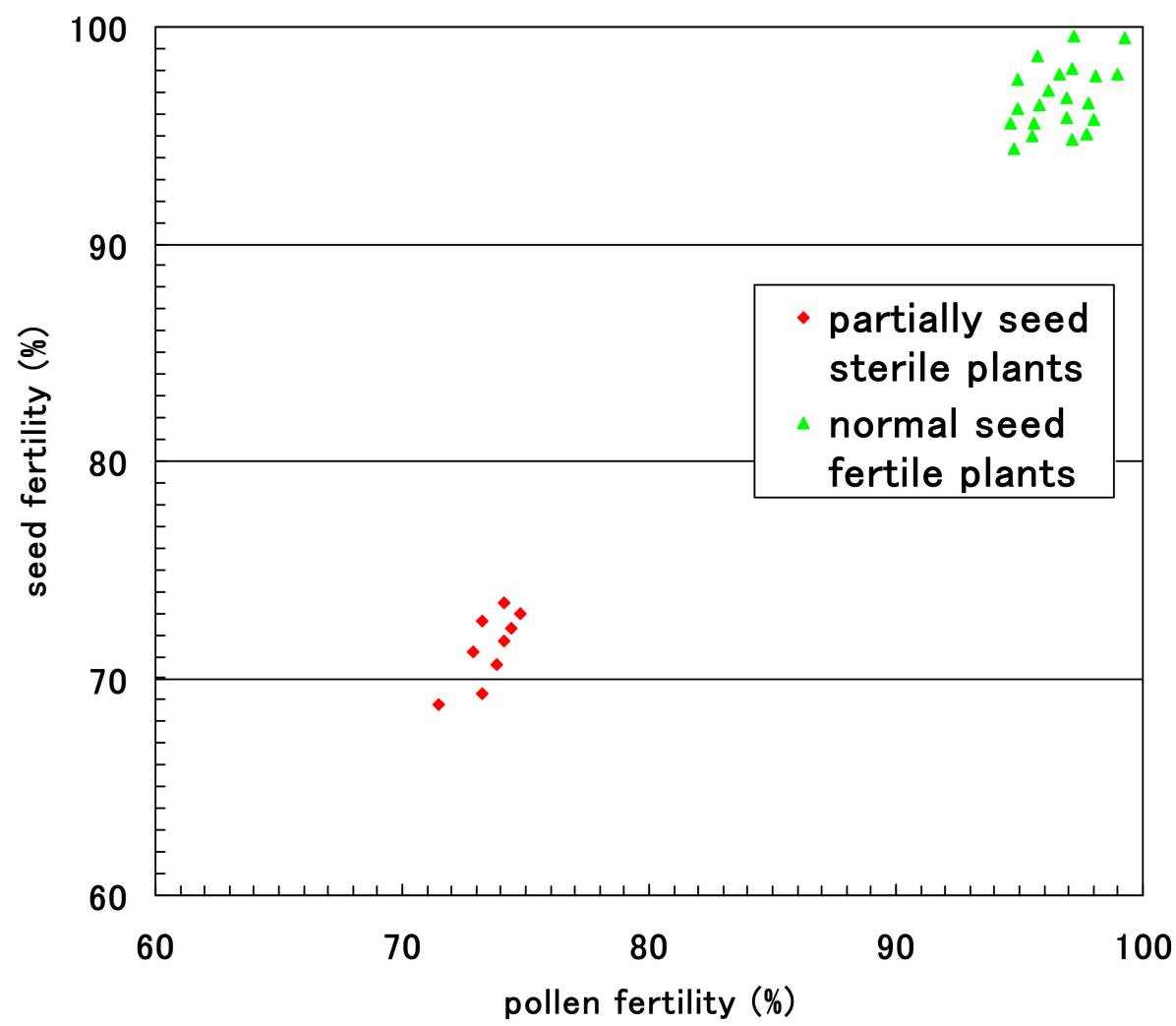

Figure 10. Relationship between pollen fertility and seed fertility in the $\mathrm{F}_{2}$ progenies of partially sterile $\mathrm{F}_{1}$ plants (D60d60Galgal) of Koshihikari $\times$ Hokuriku 100.

\section{Discussion}

The gametic lethal gene gal was identified in the present study, together with its activator $d 60$ (semidwarfing gene), in a cross between semidwarf mutant Hokuriku 100 and its original tall variety Koshihikari. The $\mathrm{F}_{2}$ progeny from these $\mathrm{F}_{1}$ hybrids displayed a unique heredity style of segregating into the ratio of 6 fertilizable long culms (4D60D60:2D60d60GalGal):2 partially non-fertilizable long culms $\left(\right.$ D60d60Galgal $=\mathrm{F}_{1}$ type $): 1$ semidwarf $($ d60d60 GalGal $)$, which deviated from the Mendelian 3:1 ratio. The appearance of partial seed sterility in $\mathrm{F}_{1}$, and $\mathrm{F}_{1}$-type partial seed sterility in many long-culm $\mathrm{F}_{2}$ plants also assisted in identification of $g a l$ and $d 60$.

Male gametes carrying gal and $d 60$ develop into lethal pollen, such that $d 60$ is not transmitted to progeny without $\mathrm{Gal}$. In other words, $\mathrm{Gal}$ is indispensable to the heredity of $d 60$. The dwarf gene $d 60$ could not have been originally obtained without the accidental simultaneous mutation of two genes, $g a l \rightarrow G a l$ and $D 60 \rightarrow d 60$. The hybrid sterile genes $g a l$ and $d 60$ identified from crosses between closely related japonica varieties differ from most known hybrid sterile genes identified from crosses between distantly related species belonging to different gene pools with reproductive barriers. This was the first discovery of a hybrid sterility gene among japonica varieties free from a reproductive barrier.

Hybrid sterility is often found among distantly related taxa of plants and animals. In rice cultivars (Oryza sativa L.), $\mathrm{F}_{1}$ hybrids between the two major subspecies, indica and japonica, usually show partial sterility of gametes [26-29]. This involves several genetic systems such as pollen sterility by the duplicate gametophytic system by recessive $s$ alleles on the two $S$ loci [30,31], female sterility caused by one-locus sporo-gametophytic allelic interaction by the single $S$ locus [32-39], and both-sex breakdown according to the one-locus gene model [40]. This hybrid sterility from indica/japonica crosses causes serious problems in developing $F_{1}$ varieties or breeding programs utilizing these divergent germplasms. 
Oka [30] proposed that duplicate $S$ gene loci, which work as developmental factors in gametes, cause hybrid sterility when the $F_{1}$ gametes receive both recessive $s$ genes on each duplicate locus. For example, if parents $\mathrm{A}$ and $\mathrm{B}$ have genotypes $s 1 / s 1+2 /+2$ and $+1 /+1 s 2 / s 2$, respectively, in which at least one + gene is necessary for normal development of the gamete, then $25 \%$ of their $\mathrm{F}_{1}$ hybrids will be sterile. This is because those gametes carrying the double recessive combination $s 1 s 2$ deteriorate due to deficiencies during gamete development. These hybrid sterility is similar to that caused by gal and $d 60$ in that two genes are responsible for both systems. However, gal and $d 60$ cause both sex sterilities, whereas Oka [31] suggests that the duplicate $s$ gene model can only explain male gamete sterility.

Kitamura [32] explained female sterility in indica/japonica hybrids by the one locus sporo-gametophytic interaction hypothesis-that is, disharmony between one allele in the gamete and another in the surrounding sporophytic tissues. This model assumes parent genotypes of $S / S$ and $S_{a} / S_{a}$ creating the hybrid $S / S_{a}$, in which allele $S$ present in the maternal tissue induces an abortion of gametes carrying the opposite allele, $S a$. Thus, $50 \%$ of $S / S a$ plants are sterile and produce gametes carrying the $S$ allele only; selfed progenies are all fertile. Ikehashi [41] showed that this one locus model was a more likely explanation for indica/japonica hybrid sterility than the two loci model $[30,31]$. The allelic interaction model [35] has been accepted as the genetic basis of hybrid sterility. According to the model, most of the sterility in $F_{1}$ hybrids is caused by an allelic interaction in the heterozygote of the $S_{5}{ }^{i}$ allele and $S_{5}{ }^{j}$ allele at the $S_{5}$ locus, where indica and japonica varieties have $S_{5}{ }^{i}$ and $S_{5}{ }^{j}$ alleles, respectively. The indica/japonica heterozygotes $\left(S_{5}{ }^{i} / S_{5}{ }^{j}\right)$ genotype is semisterile due to the partial abortion of female gametes carrying the $S_{5}{ }^{j}$ allele. On the other hand, some javanica rice varieties carry the neutral allele $S_{5}{ }^{n}$, and genotypes $S_{5}{ }^{n} / S_{5}{ }^{i}$ and $S_{5}{ }^{n} / S_{5}{ }^{j}$ do not show hybrid sterility. The donor of $S_{5}{ }^{n}$ is referred to as a wide compatible variety (WCV) [35], and this allele has been incorporated into indica and japonica varieties to overcome sterility barriers in hybrid rice breeding [42,43]. The chromosomal location of $S_{5}$ ${ }^{j}$ has been analyzed by using restriction fragment length polymorphism (RFLP) markers [44]. Thus, Qiu et al. [45] were able to delimit $S_{5}$ to a $40-\mathrm{kb}$ DNA fragment on chromosome 6, by constructing a population from a three-way cross based on near-isogenic lines (NILs) for the $S_{5}$ locus. Finally, the $S_{5}$ locus has been successfully cloned [46].

In the subsequent studies based on analyses of the fertility of a number of indica $\times$ japonica hybrids, over 30 female gametes' sterility loci, including major genes and quantitative trait loci (QTLs), were identified and mapped [47-55], or male gametes' sterility have been identified [53,56-61]. So far, indica/japonica hybrid sterility loci were identified on chromosomes 4, 6, 7, 12, and 1, which lead to female gamete abortion through allelic interactions: $S_{7}$ [47], $S_{8}$ [48], $S_{9}$, and $S_{15}$ [39] and $S_{16}$ [49], etc. Among them, the $S a$ locus has been successfully cloned [62]. One-locus allelic interactions for male sterility were also recognized in hybrids between two cultivated rice species $O$. sativa and O. glaberrima Steud. [63-65], O. sativa and O. rufipogon [66], and O. sativa and O. glumaepatula [67] and series of $S_{1}[65,68], S_{18}$ [68], $S_{20}, S_{21}[63,64], S_{22 A}$, and $S_{22 B}$ were identified [67]. Above all, hybrid sterilities in rice can be explained by a single locus allelic interaction. Therefore, hybrid sterility caused by the two genes $d 60$ and gal is an extremely rare case in rice. Moreover, gamete breakdowns of both sexes, as for gal and $d 60$, are particularly rare, with the exception of $S_{10}$, which caused a one-locus allelic interaction [69].

On the other hand, the monogenetic male-sterile gene including the photoperiod-sensitive male sterile (PGMS) and thermosensitive male sterile are useful to facilitate the production of $\mathrm{F}_{1}$ seeds [70] or the intercrossing phase of recurrent selection. Several genes for PGMS and thermosensitive male sterile were mapped or isolated [71-73]. However, their monogenetic inheritance and the expression of male sterility are certainly distinguished from the complementary sterility caused by the two genes $d 60$ and gal.

For other plant species, generally, genic models of hybrid sterility by sporo-gametophytic allelic interaction at a single locus have been proposed as gamete eliminators, which cause the abortion of gametes due to allelic interaction, and were first reported in tomato plants by Rick [74] and have since been shown to be widely distributed in interspecific plant hybrids [75]. Gametic selection in tomato 
hybrids is caused by the gamete eliminator Gep, which induces the abortion of both male and female gametes carrying the opposite allele in the heterozygote Gep/Gec [74] and the pollen killer locus [76]. In addition, the preferential transmission of alien chromosomes common to interspecific and intergeneric hybrids of Nicotiana and wheat are explained by assuming that a similar sterility factor(s) to gamete eliminator or sporo-gametophytic interaction is located on the alien chromosome [77-80]. In the case of the pollen killer locus, an alien chromosome introduced into Triticum aestivum from Aegilops triuncialis caused an inviability of gametes lacking this chromosome, resulting in the preferential transmission of the Aegilops chromosome to the offspring. A similar case of sporo-gametophytic interaction was also found between T. aestivum and Ae. longissima or Ae. sharonensis [78,81]. Above all, gametocidal genes or chromosomal fragments causing an abortion of gametes have been reported for many plant species. Accumulated evidence suggests that the phenomenon of gamete abortion through allelic interaction is widespread between distantly related taxa, serving as one of the genetic mechanisms for reproductive barriers $[64,65,82]$. Therefore, hybrid sterility caused by the two genes $d 60$ and gal is an extremely rare case in the plant kingdom.

The abnormal segregation of semidwarfness in the present study aided the discovery of the gametic lethal model composed of $d 60$ and gal. The abnormal segregation of some marker genes has been explained by their linkage to gametophytogenes, which control the fertilization ability of pollen. Rice has 10 gametophytogenes that are designated $g a-1$ to $g a-10$, some of which have been mapped onto four loci [83-89]. Although many genes were reported from varietal crosses within O. sativa [85-87,90], these gametophytogenes did not cause seed sterility. Therefore, it was apparent that gal differed from gametophytogenes in this way. In addition, segregation distortion was observed at a number of loci in inter-subspecific hybrids [91-93].

If $\mathrm{Gal}$ had not originally mutated from gal together with the induction of $d 60$ from $D 60, d 60$ would have been eliminated by the lethality of $\mathrm{M}_{1}$ gametes, and gal would not have been identified as a gametic lethal gene. Thus, $d 60$ and its transmitter $\mathrm{Gal}$ are rare and valuable mutant genes forwarding semidwarf breeding as an alternative of $s d 1$. For the practical use of $d 60$ in semidwarf breeding programs, line $\mathrm{D} 60 \mathrm{D} 60 \mathrm{GalGal}$ is a special class of germplasm that is capable of producing fertile hybrids when crossed with Hokuriku 100. The early mutation breeding program to create semidwarf Koshihikari, before the Hokuriku National Agricultural Experiment Station, was unsuccessful. Then, Samoto and Kanai [20] enlarged the scale of mutation breeding using 200,000 $\mathrm{M}_{1}$ plants. This led to the selection of a semidwarf line Hokuriku 100 from $\mathrm{M}_{5}$ plants derived from 298 short mutants selected from $80,000 \mathrm{M}_{2}$ plants. The appearance rate of short mutants at $0.3 \%$ was much lower than the $11.0 \%$ observed for wheat [94] and the 5.2\% observed for barley [95], which may be a result of gametic lethality by interactions between $g a l$ and induced dwarf genes.

Extensive typhoon damage from the lodging of rice has become a serious problem in recent years, and developing new varieties of typhoon-resistant rice through the introduction of semidwarf genes is an urgent task. There are high expectations of 'Hikarishinseiki' (Hikari New Century) [96], which is a new lodging-resistant, high-yield, tasty variety developed through the introduction of the semidwarf gene $s d 1$ to Koshihikari. However, in consideration of the maintenance and expansion of genetic diversity, this gene should not be solely relied upon for the development of semidwarf varieties. Through this study, we identified a new semidwarfing gene $d 60$, which shows strong lodging-resistance, and genetically independence from $s d 1$ [23]. Further research could elucidate the function of $d 60$ and enable the development of novel semidwarf rice varieties.

\section{Conclusions}

The gametic lethal gene gal in combination with the semidwarfing gene $d 60$ causes complementary gamete lethality in rice. Through $\mathrm{F}_{2}$ to $\mathrm{F}_{4}$ derived from the cross between D60gal-homozygous (tall) and $160 \mathrm{Gal}$-homozygous (semidwarf), progenies of $\mathrm{F}_{1}$ and partial sterile plants (D60d60Galgal) segregated in a ratio of 1 semidwarf $(1 \mathrm{~d} 60 \mathrm{~d} 60 \mathrm{GalGal}): 2$ tall and quarter sterile (2 D60d60Galgal):6 tall (2 D60d60GalGal:1 D60D60GalGal:2 D60D60Galgal:1 D60D60galgal), which is skewed from the 
Mendelian ratio of 1 semidwarf: 3 tall. Through $\mathrm{F}_{3}$ to $\mathrm{F}_{4}$, progenies of fertile and tall heterozygous plants (D60d60GalGal) segregated in the Mendelian ratio of 1[semidwarf (d60d60GalGal)]:2[1 semidwarf:3 tall (D60d60GalGal)]:1[tall (D60D60GalGal)]. The backcrossing of D60Gal-homozygous tall $\mathrm{F}_{4}$ plants with d60 Gal-homozygous plants resulted in fertile and tall $\mathrm{BCF}_{1}(\mathrm{D} 60 \mathrm{~d} 60 \mathrm{GalGal})$, and $\mathrm{BCF}_{2}$ segregated in 1 semidwarf (d60d60GalGal)]:3 tall (2 D60d60GalGal:1 D60D60 Gal Gal), proving that $d 60$ is transmitted as a single recessive gene in the $D 60 \mathrm{~d} 60 \mathrm{GalGal}$ genetic background (i.e., in the absence of gal). Further, gal was localized on chromosome 5, which was evident from the deviated 1:8 segregation of linked gene $d 1$ and molecular fine mapping using SSR markers. Next-generation sequencing identified the candidate SNP responsible for Gal located at 7,005,876 bp from the end of the short arm of chromosome 5 in the Koshihikri genome. Pollens genotype $160 \mathrm{gal}$ began to degrade at the binucleate stage and lost vegetative nuclei. However, it underwent second pollen mitosis, raising two generative nuclei still in a small abortive pollen. Thus, our study describes a novel genetic mode bearing a reproductive barrier. This is the first report on such a complementary lethal gene, whose mutation allows the transmission of a co-induced valuable semidwarfng gene $d 60$.

Author Contributions: Conceptualization, M.T.; methodology, M.T.; investigation, M.T.; resources, M.T. and T.T.; writing—original draft preparation, M.T.; writing—review and editing, M.T.; project administration, M.T.; funding acquisition, M.T.

Funding: This work is founded by Adaptable and Seamless Technology Transfer Program (A-STEP) through Target-driven R\&D (high-risk challenge type) by Japan Science and Technology Agency (JST) to Motonori Tomita, whose project ID14529973 was entitled "NGS genome-wide analysis-based development of rice cultivars with super high-yield, large-grains, and early/late flowering suitable for the globalized world and global warming", since 2014 to 2018.

Acknowledgments: The author thanks to Masahiro Yano for his kind issue of KF2-11-75. The author also thanks to Prof. Atsushi Yoshimura for his kind issue of marker gene lineage.

Conflicts of Interest: The authors declare no conflict of interest.

\section{References}

1. Khush, G.S. Green revolution: Preparing for the 21st century. Genome 1999, 42, 646-655. [CrossRef] [PubMed]

2. Hergrove, T.; Coffman, W.R. Breeding History. In Rice that Changed the World: Cerebrating 50 Years of IR8; Rice Today: Laguna, Philippines, 2016; pp. 6-10.

3. Jennings, P. Rice revolutions in Latin America. In Rice that Changed the World: Cerebrating 50 Years of IR8; Rice Today: Laguna, Philippines, 2016; p. 19.

4. Cho, Y.G.; Eun, M.Y.; Kim, Y.K.; Chung, T.Y.; Chae, Y.A. The semidwarf gene, sd-1, of rice (Oryza sativa L). 1. Linkage with the esterase locus, EstI-2. Theor. Appl. Genet. 1994, 89, 49-53. [CrossRef] [PubMed]

5. Cho, Y.G.; Eun, M.Y.; McCouch, S.R.; Chae, Y.A. The semidwarf gene, sd-1, of rice (Oryza sativa L.) 2 Molecular mapping and marker-assisted selection. Theor. Appl. Genet. 1994, 89, 54-59. [CrossRef] [PubMed]

6. Maeda, H.; Ishii, T.; Mori, H.; Kuroda, J.; Horimoto, M.; Takamure, I.; Kinoshita, T.; Kamijima, O. High density molecular map of semidwarfing gene, sd-1, in rice (Oryza sativa L.). Breed. Sci. 1997, 47, 317-320. [CrossRef]

7. Sasaki, A.; Ashikari, M.; Ueguchi-Tanaka, M.; Itoh, H.; Nishimura, A.; Swapan, D.; Ishiyama, K.; Saito, T.; Kobayashi, M.; Khush, G.S.; et al. Green revolution: A mutant gibberellin-synthesis gene in rice. Nature 2002, 416, 701-702. [CrossRef]

8. Monna, L.; Kitazawa, N.; Yoshino, R.; Suzuki, J.; Masuda, H.; Maehara, Y.; Tanji, M.; Sato, M.; Nasu, S.; Minobe, Y. Positional cloning of rice semidwarfing gene, sd-1: Rice "Green revolution gene" encodes a mutant enzyme involved in gibberellin synthesis. DNA Res. 2002, 9, 11-17. [CrossRef]

9. Spielmeyer, W.; Ellis, M.H.; Chandler, P.M. Semidwarf (sd-1), "green revolution" rice, contains a defective gibberellin 20-oxidase gene. Proc. Natl. Acad. Sci. USA 2002, 99, 9043-9048. [CrossRef]

10. Ashikari, M.; Sasaki, A.; Ueguchi-Tanaka, M.; Itoh, H.; Nishimura, A.; Datta, S.; Ishiyama, K.; Saito, T.; Kobayashi, M.; Khush, G.S.; et al. Loss-of-function of a rice gibberellin biosynthetic gene, GA20 oxidase (GA20ox-2), led to the rice 'green revolution'. Breed. Sci. 2002, 52, 143-150. [CrossRef]

11. Hedden, P. Constructing dwarf rice. Nat. Biotechnol. 2003, 21, 873-874. [CrossRef] 
12. Hedden, P. The genes of the Green Revolution. Trends Genet. 2003, 19, 5-9. [CrossRef]

13. Tomita, M.; Ishii, K. Genetic performance of the semidwarfing allele sd1 derived from a Japonica rice cultivar and minimum requirements to detect its single-nucleotide polymorphism by MiSeq whole-genome sequencing. BioMed. Res. Int. 2018, 2018, 4241725. [CrossRef] [PubMed]

14. Foster, K.W.; Rutger, J.N. Inheritance of semidwarfism in rice, Oryza sativa L. Genetics 1978, 88, 559-574. [PubMed]

15. Kikuchi, F.; Itakura, N.; Ikehashi, H.; Yokoo, M.; Nakane, A.; Maruyama, K. Genetic analysis of semidwarfism in high-yielding rice varieties in Japan. Bull. Natl. Inst. Agric. Sci. 1985, 36, 125-145.

16. Kikuchi, F.; Futsuhara, Y. Inheritance of Morphological Characters 2, Inheritance of Semidwarf. In Science of the Rice Plant; Matsuo, T., Shimizu, S., Tsunoda, S., Murata, Y., Kumazawa, K., Futsuhara, Y., Hoshikawa, K., Yamaguchi, H., Kikuchi, F., Eds.; Tokyo Food and Agricultural Policy Research Center: Tokyo, Japan, 1997; Volume 3, pp. 309-317.

17. Itoh, H.; Tatsumi, T.; Sakamoto, T.; Otomo, K.; Toyomasu, T.; Kitano, H.; Ashikari, M.; Ichihara, S.; Matsuoka, M. A rice semi-dwarf gene, Tan-Ginbozu (D35), encodes the gibberellin biosynthesis enzyme, ent-kaurene oxidase. Plant Mol. Biol. 2004, 54, 533-547. [CrossRef] [PubMed]

18. Tong, H.; Jin, Y.; Liu, W.; Li, F.; Fang, J.; Yin, Y.; Qian, Q.; Zhu, L.; Chu, C. DWARF AND LOW-TILLERING, a new member of the GRAS family, plays positive roles in brassinosteroid signaling in rice. Plant J. 2009, 58, 803-816. [CrossRef] [PubMed]

19. Zhang, J.; Liu, X.; Li, S.; Cheng, Z.; Li, C. The rice semi-dwarf mutant sd37, caused by a mutation in CYP96B4, plays an important role in the fine-tuning of plant growth. PLoS ONE 2014, 9, e88068. [CrossRef]

20. Samoto, S.; Kanai, D. Studies on the mutation breeding in rice. I. Short stiff mutations induced by gamma-ray irradiation to the rice variety Koshihikari. Jpn. J. Breed. 1975, 12, 1-7. [CrossRef]

21. Tomita, M.; Tanisaka, T.Y.; Yamagata, H. Linkage Analysis for the Gametic Lethal Gene of Rice Variety Koshihikari and the Semidwarf Gene Induced in Koshihikari. In The Key to the Survival of the Earth, Proceedings of the 6th International Congress of the Society for the Advancement of Breeding Researches in Asia and Oceania (SABRAO), Tsukuba, Japan, 21-25 August 1989; Iyama, S., Takeda, G., Eds.; FAO/IAEA Division of Nuclear Techniques in Food and Agriculture: Vienna, Austria, 1990; pp. 345-348.

22. Tanisaka, T.; Tomita, M.; Yamagata, H. Gene analysis for the semidwarfism of two mutant strains, Hokuriku 100 and Kanto 79, induced from a rice variety Koshihikari. Studies on on the utility of artificial mutations in plant breeding XVIII. Jpn. J. Breed. 1990, 40, 103-117. [CrossRef]

23. Tomita, M. Combining two semidwarfing genes $d 60$ and $s d 1$ for reduced height in 'Minihikari', a new rice germplasm in the 'Koshihikari' genetic background. Genet. Res. 2012, 94, 235-244. [CrossRef]

24. Kihara, H.; Hirayoshi, I. Development of pollens in Oryza sativa L. Agric. Hortic. 1942, 17, 685-689.

25. Tomita, M.; Yamagata, H.; Tanisaka, T. Developmental Cytology on Gametic Abortion Caused by Induced Complementary Genes gal and $d 60$ in Japonica Rice. In Advances in Rice Genetics, Proceedings of the International Rice Genetics Symposium, Manila, Philippines, 27-31 May 1985; International Rice Research Institute: Manila, Philippines, 2003; pp. 178-181.

26. Kato, S.; Kosaka, H.; Hara, S. Classification of improved rice varieties. J. Kyushu Imp. Univ. Agric. 1928, 3, 132-147.

27. Kato, S. On the affinity of rice varieties as shown by the fertility of rice plants. Cent. Agric. Inst. Kyushu Imp. Univ. 1930, 2, 241-276.

28. Oka, H.I. Genic analysis for the sterility of hybrids between distantly related varieties of cultivated rice. J. Genet. 1957, 55, 397-409. [CrossRef]

29. Oka, H.I. Origin of Cultivated Rice; Japan Science Social Press/Elsevier: Tokyo, Japan, 1988.

30. Oka, H.I. The mechanism of sterility in the intervarietal hybrid. (Phylogenetic differentiation of the cultivated rice plant. VI.). Jpn. J. Breed. 1953, 2, 217-224. [CrossRef]

31. Oka, H.I. Analysis of genes controlling $F_{1}$ sterility in rice by the use of isogenic lines. Genetics 1974, 77 , 521-534.

32. Kitamura, E. Genetic studies on sterility observed in hybrids between distantly related varieties of rice, Oryza sativa L. Bull. Chugoku Agric. Exp. Sta. Ser. A 1962, 8, 141-205.

33. Oka, H.I. Considerations on the Genetic Basis of Intervarietal Sterility in Oryza sativa. In Rice Genetics and Cytogenetics; Elsevier: Amsterdam, The Netherlands, 1964; pp. 158-174. 
34. Ikehashi, H.; Araki, H. Varietal screening of compatibility types revealed in $\mathrm{F}_{1}$ fertility of distant crosses in rice. Jpn. J. Breed. 1984, 34, 304-313. [CrossRef]

35. Ikehashi, H.; Araki, H. Genetics of $\mathrm{F}_{1}$ Sterility in Remote Crosses of Rice. In Rice Genetics, Proceedings of the International Rice Genetics Symposium, Manila, Philippines, 27-31 May 1985; International Rice Research Institute: Manila, Philippines, 1986; pp. 119-130.

36. Ikehashi, H.; Araki, H. Multiple alleles controlling $\mathrm{F}_{1}$ sterility in remote crosses of rice (Oryza sativa). Jpn. J. Breed. 1988, 38, 283-291. [CrossRef]

37. Ikehashi, H.; Araki, H.; Yanagihara, S. Screening and Analysis of Wide Compatibility Loci in Wide Crosses of Rice. In Rice Genetics II, Proceedings of the Second International Rice Genetics Symposium, Manila, Philippines, 14-18 May 1990; International Rice Research Institute: Manila, Philippines, 1991; pp. 33-43.

38. Ikehashi, H.; Wan, J. Differentiation of Alleles at Seven Loci for Hybrid Sterility in Cultivated Rice (Oryza sativa L.). In Rice Genetics III, Proceedings of the Third International Rice Genetics Symposium, Manila, Philippines, 16-20 October 1995; Khush, G.S., Ed.; International Rice Research Institute: Manila, Philippines, 1996; pp. 404-408.

39. Wan, J.; Yamaguchi, Y.; Kato, H.; Ikehashi, H. Two new loci for hybrid sterility in cultivated rice (Oryza sativa L.). Theor. Appl. Genet. 1996, 92, 183-190. [CrossRef]

40. Sano, Y.; Sano, R.; Eiguchi, M.; Hirano, H.Y. Gamete eliminator adjacent to the $w x$ locus as revealed by pollen analysis in rice. J. Hered. 1994, 85, 310-312. [CrossRef]

41. Ikehashi, H. Theory and application for $\mathrm{F}_{1}$ fertility in remote cross of rice. Agric. Hortic. 1985, 60, $1099-1104$.

42. Ikehashi, H. Genetics of Hybrid Sterility in Wide Hybridization in Rice. In Biotechnology in Agriculture and Forestry; Bajaj, Y.P.S., Ed.; Springer: Berlin/Heidelberg, Germany, 1991; Volume 14, pp. 113-127.

43. Yuan, L.P. The Strategy of the Development of Hybrid Rice Breeding. In Current Status of Two Line Hybrid Rice Research; Yuan, L.P., Ed.; Agricultural Publishing Ltd.: Beijing, China, 1992; pp. 1-5.

44. Yanagihara, S.; McCouch, S.R.; Ishikawa, K.; Ogi, Y.; Maruyama, K.; Ikehashi, H. Molecular analysis of the inheritance of the $S-5$ locus, conferring wide compatibility in Indica/Japonica hybrids of rice (Oryza sativa L.). Theor. Appl. Genet. 1995, 90, 182-188. [CrossRef] [PubMed]

45. Qiu, S.Q.; Liu, K.; Jiang, J.X.; Song, X.; Xu, C.G.; Li, X.H.; Zhang, Q. Delimitation of the rice wide compatibility gene $S_{5}{ }^{n}$ to a 40-kb DNA fragment. Theor. Appl. Genet. 2005, 111, 1080-1086. [CrossRef] [PubMed]

46. Chen, J.; Ding, J.; Ouyang, Y.; Du, H.; Yang, J.; Cheng, K.; Zhao, J.; Qiu, S.; Zhang, X.; Yao, J.; et al. A triallelic system of $S 5$ is a major regulator of the reproductive barrier and compatibility of indica-japonica hybrids in rice. Proc. Natl. Acad. Sci. USA 2008, 105, 11436-11441. [CrossRef] [PubMed]

47. Yanagihara, S.; Kato, H.; Ikehashi, H. A new locus for multiple alleles causing hybrid sterility between an Aus variety and Javanica varieties in rice (Oryza sativa L.). Jpn. J. Breed. 1992, 42, 793-801. [CrossRef]

48. Wan, J.; Yanagihara, S.; Kato, H.; Ikehashi, H. Multiple alleles at a new locus hybrid sterility between a Korean Indica variety and a Javanica variety in rice (Oryza sativa L.). Jpn. J. Breed. 1993, 43, 507-516.

49. Wan, J.; Ikehashi, H. Identification of a new locus $S-16$ causing hybrid sterility in native rice varieties (Oryza sativa L.) from Tai-hu Lake region and Yunnan Province, China. Breed. Sci. 1995, 45, 461-470. [CrossRef]

50. Liu, K.D.; Wang, J.; Li, H.B.; Xu, C.G.; Liu, A.M.; Li, X.H.; Zhang, Q. A genome-wide analysis of wide compatibility in rice and the precise location of the $S 5$ locus in the molecular map. Theor. Appl. Genet. 1997, 95, 809-814. [CrossRef]

51. Wang, J.; Liu, K.D.; Xu, C.G.; Li, X.H.; Zhang, Q.F. The high level of wide compatibility of variety 'Dular' has a complex genetic basis. Theor. Appl. Genet. 1998, 97, 407-412. [CrossRef]

52. Liu, Y.S.; Zhu, L.H.; Sun, J.S.; Chen, Y. Mapping QTLs for defective female gametophyte development in an inter-subspecific cross in Oryza sativa L. Theor. Appl. Genet. 2001, 102, 1243-1251. [CrossRef]

53. Song, X.; Qiu, S.Q.; Xu, C.G.; Li, X.H.; Zhang, Q. Genetic dissection of embryo sac fertility, pollen fertility, and their contributions to spikelet fertility of intersubspecific hybrids in rice. Theor. Appl. Genet. 2005, 110, 205-211. [CrossRef] [PubMed]

54. Zhu, S.; Wang, C.; Zheng, T.; Zhao, Z.; Ikehashi, H.; Wan, J. A new gene located on chromosome 2 causing hybrid sterility in a remote cross of rice. Plant Breed. 2005, 124, 440-445. [CrossRef]

55. Zhao, Z.; Wang, C.; Jiang, L.; Zhu, S.; Ikehashi, H.; Wan, J. Identification of a new hybrid sterility gene in rice (Oryza sativa L.). Euphytica 2006, 151, 331-337. [CrossRef]

56. Zhang, G.Q.; Lu, Y.G. Genetic studies of the hybrid sterility in cultivated rice (Oryza sativa). I. Diallel analysis of the hybrid sterility among isogenic $\mathrm{F}_{1}$ sterile lines. Chin. J. Rice Sci. 1989, 3, 97-101. 
57. Zhang, G.Q.; Lu, Y.G. Genetic studies of the hybrid sterility in cultivated rice (Oryza sativa) II. A genic model for $\mathrm{F}_{1}$ pollen sterility. Acta Genet. Sin. 1993, 20, 222-228.

58. Zhang, Q.F.; Shen, B.Z.; Dai, X.K.; Mei, M.H.; Maroof, M.A.S.; Li, Z.B. Using bulked extremes and recessive class to map genes for photoperiod-sensitive genic male-sterility in rice. Proc. Natl. Acad. Sci. USA 1994, 91, 8675-8679. [CrossRef]

59. Zhang, R.I.; Xue, G.X.; Song, J.X.; Jiang, X.W. Abnormality in male organ development and fertility of photoperiod-sensitive genic male sterile rice plants under short day condition. Acta Bot. Sin. 1999, 41, 1317-1323.

60. Li, W.T.; Zeng, R.Z.; Zhang, Z.M.; Zhang, G.Q. Mapping of $S-b$ locus for $F_{1}$ pollen sterility in cultivated rice using PCR based markers. Acta Bot. Sin. 2002, 44, 463-467.

61. Wang, G.W.; He, Y.Q.; Xu, C.G.; Zhang, Q.F. Fine mapping of $\mathrm{f}_{5}$-Du, a gene conferring wide-compatibility for pollen fertility in inter-subspecific hybrids of rice (Oryza sativa L.). Theor. Appl. Genet. 2006, 112, 382-387. [CrossRef]

62. Long, Y.; Zhao, L.; Niu, B.; Su, J.; Wu, H.; Chen, Y.; Zhang, Q.; Guo, J.; Zhuang, C.; Mei, M.; et al. Hybrid male sterility in rice controlled by interaction between divergent alleles of two adjacent genes. Proc. Natl. Acad. Sci. USA 2008, 105, 18871-18876. [CrossRef]

63. Sano, Y.; Chu, Y.E.; Oka, H.I. Genetic studies of speciation in cultivated rice. 1. Genic analysis for the $\mathrm{F}_{1}$ sterility between Oryza sativa L. and Oryza glaberrima Steud. Jpn. J. Genet. 1979, 54, 121-132. [CrossRef]

64. Sano, Y. A new gene controlling sterility in $\mathrm{F}_{1}$ hybrids of two cultivated rice species. J. Hered. 1983, 74, 435-439. [CrossRef]

65. Sano, Y. The genetic nature of gamete eliminator in rice. Genetics 1990, 125, 183-191. [PubMed]

66. Sano, Y. Genetic comparisons of chromosome 6 between wild and cultivated rice. Jpn. J. Breed. 1992, 42, 561-572. [CrossRef]

67. Sakata, M.; Yamagata, Y.; Doi, K.; Yoshimura, A. Two linked genes on rice chromosome 2 for $\mathrm{F}_{1}$ pollen sterility in a hybrid between Oryza sativa and O. glumaepatula. Breed. Sci. 2014, 64, 309-320. [CrossRef] [PubMed]

68. Doi, K.; Yoshimura, A.; Iwata, N. RFLP mapping and QTL analysis of heading date and pollen sterility using backcross populations between Oryza sativa L. and Oryza glaberrima Steud. Breed. Sci. 1998, 48, 395-399. [CrossRef]

69. Sano, Y. Pollen-killers in rice. Jpn. J. Breed. 1994, 44, 298.

70. Chang, Z.; Chen, Z.; Wang, N.; Xie, G.; Lu, J.; Yan, W.; Zhou, J.; Tang, X.; Deng, X.W. Construction of a male sterility system for hybrid rice breeding and seed production using a nuclear male sterility gene. Proc. Natl. Acad. Sci. USA 2016, 113, 14145-14150. [CrossRef]

71. Qi, Y.; Liu, Q.; Zhang, L.; Mao, B.; Yan, D.; Jin, Q.; He, Z. Fine mapping and candidate gene analysis of the novel thermo-sensitive genic male sterility tms9-1 gene in rice. Theor. Appl. Genet. 2014, 127, 1173-1182. [CrossRef]

72. Frouin, J.; Filloux, D.; Taillebois, J.; Grenier, C.; Montes, F.; De Lamotte, F.; Jean-Luc, V.; Brigitte, C.; Nourollah, A. Positional cloning of the rice male sterility gene ms-IR36, widely used in the inter-crossing phase of recurrent selection schemes. Mol. Breed. 2014, 33, 555-567. [CrossRef]

73. Charleswotth, D. Origins of rice cytoplasmic male sterility genes. Cell Res. 2017, 27, 3-4. [CrossRef] [PubMed]

74. Rick, C.M. Abortion of male and female gametes in the tomato determined by allelic interaction. Genetics 1966, 53, 85-96. [PubMed]

75. Sano, Y. Is an egg-killer present in rice. Theor. Appl. Genet. 1993, 86, 1038-1042. [CrossRef] [PubMed]

76. Loegerlng, W.G.; Sears, E.R. Distorted inheritance of stem rust resistance of Timstein wheat caused by a pollen-killing gene. Can. J. Genet. Cytol. 1963, 5, 67-72.

77. Cameron, D.R.; Moav, R. Inheritance in Nicotiana tubucum XXVII: Pollen Killer, an alien genetic locus inducing abortion of microspores not carrying it. Genetics 1957, 42, 326-335.

78. Maan, S.S. Cytoplasmic Variability and Speciation in Triticinae. In Prairie: A Multiple View; Wall, M.K., Ed.; University North Dakoda Press: Grand Forks, ND, USA, 1975; pp. 255-281.

79. Endo, T.R.; Tsunewaki, K. Sterility of common wheat with Aegilops triuncialis cytoplasm. J. Hered. 1975, 66, 13-18. [CrossRef]

80. Kibirige-Sebunya, I.; Knott, D.R. Transfer of stem rust resistance to wheat from an Agropyron chromosome having a gametocidal effect. Can. J. Genet. Cytol. 1983, 25, 215-221. [CrossRef] 
81. Maan, S.S. Cytoplasmic homology between Aegilops squarrosa L. and Ae. cylindrica HOST. Crop. Sci. 1976, 16, 757-761. [CrossRef]

82. Scoles, G.J.; Kibirige-Sebunya, I.N. Preferential abortion of gametes in wheat induced by an Agropyron chromosome. Can. J. Genet. Cytol. 1983, 25, 1-6. [CrossRef]

83. Iwata, N.; Nagamatsu, T.; Omura, T. Abnormal segregation of waxy and apiculus coloration by a gametophyte gene belonging to the first linkage group in rice. Jpn. J. Breed. 1964, 14, 33-39. [CrossRef]

84. Nakagahra, M. Genetic mechanism on the distorted segregation of marker genes belonging to the eleventh linkage group in cultivated rice. Jpn. J. Breed. 1972, 22, 232-238. [CrossRef]

85. Nakagahra, M.; Omura, T.; Iwata, N. Gametophyte genes and their loci on the eleventh linkage group of cultivated rice. Jpn. J. Breed. 1972, 22, 305-312. [CrossRef]

86. Nakagahra, M.; Omura, T.; Iwata, N. New certation gene on the first linkage group found by inter-subspecific hybridization of cultivated rice. J. Fac. Agric. Kyushu Univ. 1974, 19, 157-167.

87. Mori, K.; Kinoshita, T.; Takahashi, M. Segregation distortion and its causation of an endosperm character in crosses of distantly related rice varieties. Genetical studies on rice plant, LVIII. Mem. Fac. Agric. Hokkaido Univ. 1973, 9, 74-86.

88. Maekawa, M.; Kinoshita, T.; Takahashi, M. A new gametophyte gene in the second linkage group of rice. J. Fac. Agric. Hokkaido Univ. 1981, 60, 107-114.

89. Maekawa, M.; Kita, F. New gametophyte genes located in the third linkage group (Chromosome 3) of rice. Jpn. J. Breed. 1985, 35, 25-31. [CrossRef]

90. Kinoshita, T.; Takamure, I. Inheritance and linkage relationship on zebra chlorosis and zebra necrosis in rice. Genetical studies on rice plant, LXXXVIII. J. Fac. Agric. Hokkaido Univ. 1984, 61, 445-455.

91. Lin, S.Y.; Ikehashi, H.; Yanagihara, S.; Kawashima, A. Segregation distortion via male gametes in hybrids between indica and japonica or wide-compatibility varieties of rice (Oryza sativa L). Theor. Appl. Genet. 1992, 84, 812-818. [CrossRef]

92. Kinoshita, T. Report of committee on gene symbolization, nomenclature and linkage groups. Rice Genet. Newls. 1995, 12, 9-115.

93. Lu, C.G.; Takabatake, K.; Ikehashi, H. Identification of segregation-distortion-neutral alleles to improve pollen fertility of indica-japonica hybrids in rice (Oryza sativa L.). Euphytica 2000, 113, 101-107. [CrossRef]

94. Kaizuma, N.; Hirano, J.; Gotoh, T. Breeding of wheat strains with short and stiff culm by r-ray irradiation and some experimental results related to mutation breeding method. Bull. Chugoku Agric. Exp. Stn. 1967, 14, $1-21$.

95. Toda, M.; Nakada, T.; Miki, S.; Tsukada, T. Studies on mutation breeding in barley and wheat plants. II. Breeding of a new variety and desirable short-culm strains in wheat by gamma-ray irradiations. Jpn. J. Breed. 1972, 22, 239-245. [CrossRef]

96. Tomita, M. Introgression of Green Revolution $s d 1$ gene into isogenic genome of rice super cultivar Koshihikari to create novel semidwarf cultivar 'Hikarishinseiki' (Koshihikari-sd1). Field Crops Res. 2009, 114, 173-181. [CrossRef]

(C) 2019 by the authors. Licensee MDPI, Basel, Switzerland. This article is an open access article distributed under the terms and conditions of the Creative Commons Attribution (CC BY) license (http://creativecommons.org/licenses/by/4.0/). 